\title{
Methodology for Estimating Safe Charge Limits of Flammable Refrigerants in HVAC\&R Applications - Part 2
}

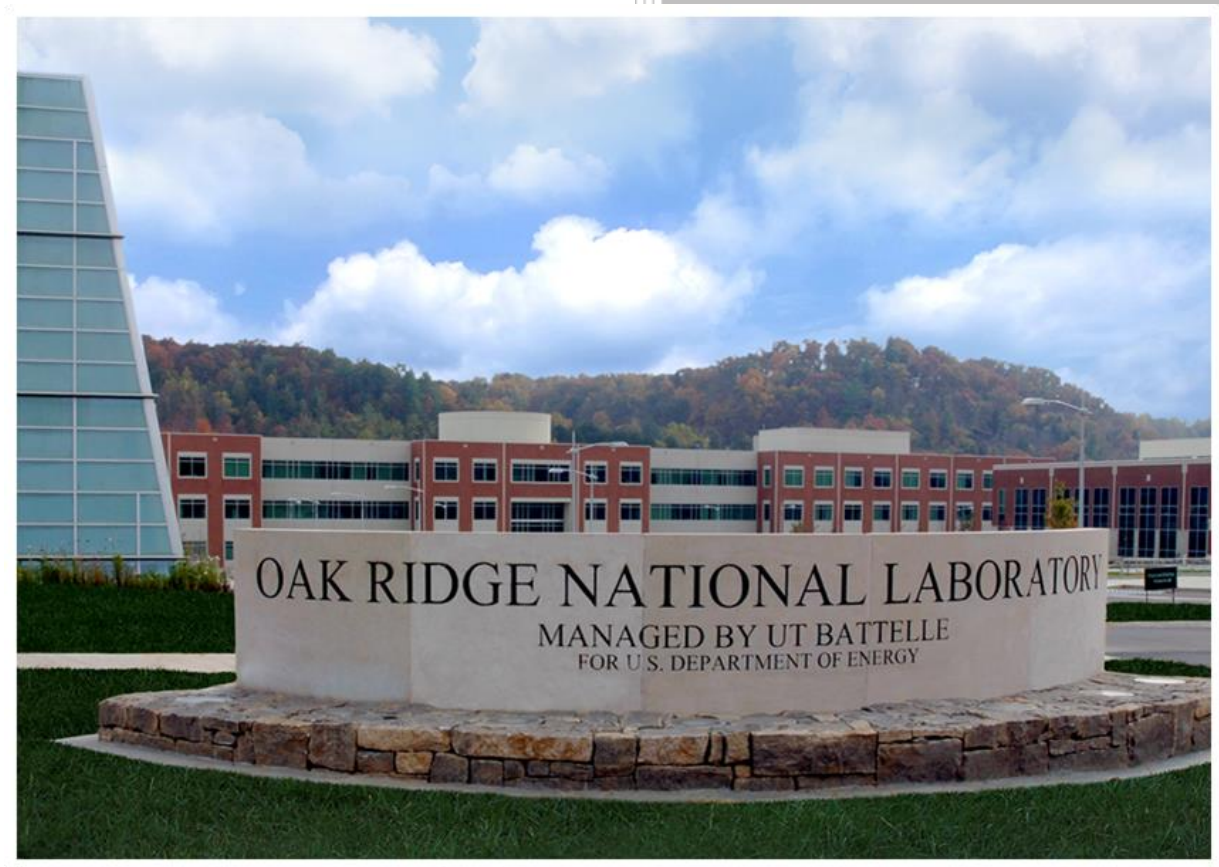

\section{Approved for public release.} Distribution is unlimited.
Omar Abdelaziz Ahmad Abu-Heiba Van Baxter Dean Edwards Ahmed Elatar Charles E.A. Finney Viral K. Patel Miroslav Stoyanov Mingkan Zhang

March 31, 2019 


\title{
DOCUMENT AVAILABILITY
}

Reports produced after January 1, 1996, are generally available free via US Department of Energy (DOE) SciTech Connect.

Website www.osti.gov

Reports produced before January 1, 1996, may be purchased by members of the public from the following source:

\author{
National Technical Information Service \\ 5285 Port Royal Road \\ Springfield, VA 22161 \\ Telephone 703-605-6000 (1-800-553-6847) \\ TDD 703-487-4639 \\ Fax 703-605-6900 \\ E-mail info@ntis.gov \\ Website http://classic.ntis.gov/
}

Reports are available to DOE employees, DOE contractors, Energy Technology Data Exchange representatives, and International Nuclear Information System representatives from the following source:

Office of Scientific and Technical Information

PO Box 62

Oak Ridge, TN 37831

Telephone 865-576-8401

Fax 865-576-5728

E-mail reports@osti.gov

Website http://www.osti.gov/contact.html

This report was prepared as an account of work sponsored by an agency of the United States Government. Neither the United States Government nor any agency thereof, nor any of their employees, makes any warranty, express or implied, or assumes any legal liability or responsibility for the accuracy, completeness, or usefulness of any information, apparatus, product, or process disclosed, or represents that its use would not infringe privately owned rights. Reference herein to any specific commercial product, process, or service by trade name, trademark, manufacturer, or otherwise, does not necessarily constitute or imply its endorsement, recommendation, or favoring by the United States Government or any agency thereof. The views and opinions of authors expressed herein do not necessarily state or reflect those of the United States Government or any agency thereof. 
Energy and Transportation Science Division

\title{
METHODOLOGY FOR ESTIMATING SAFE CHARGE LIMITS OF FLAMMABLE REFRIGERANTS IN HVAC\&R APPLICATIONS - PART 2
}

\author{
Reduced Order Model (ROM) Development \\ Omar Abdelaziz \\ Ahmad Abu-Heiba \\ Van Baxter \\ Dean Edwards \\ Ahmed Elatar \\ Charles E.A. Finney \\ Viral K. Patel \\ Miroslav Stoyanov \\ Mingkan Zhang
}

Date Published: March 31, 2019

Prepared by

OAK RIDGE NATIONAL LABORATORY

Oak Ridge, TN 37831-6283

managed by

UT-BATTELLE, LLC

for the

US DEPARTMENT OF ENERGY

under contract DE-AC05-00OR22725 



\section{CONTENTS}

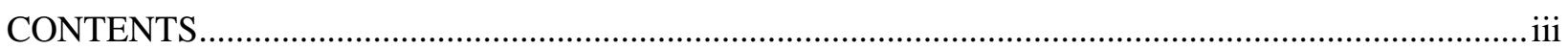

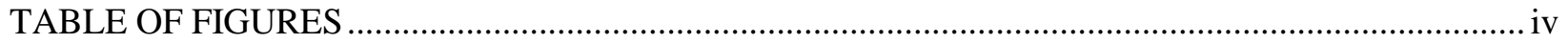

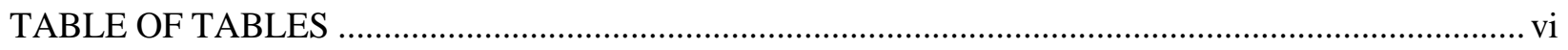

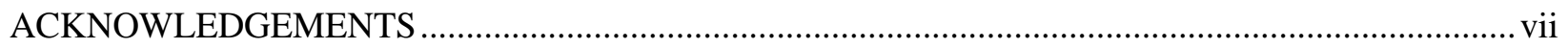

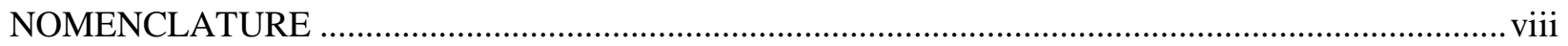

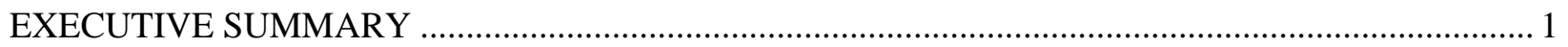

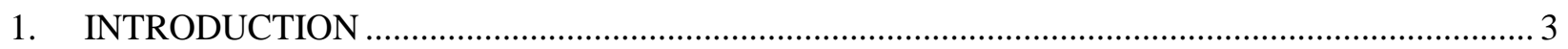

2. REDUCED ORDER MODEL DEVELOPMENT APPROACH …............................................. 5

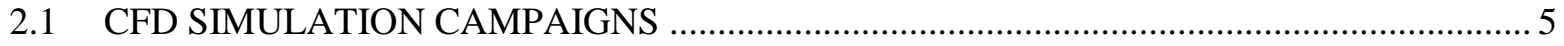

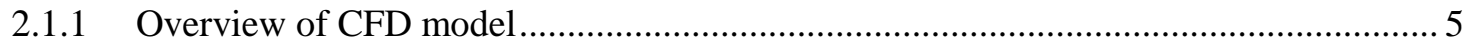

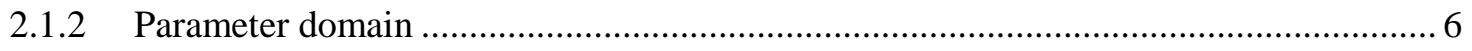

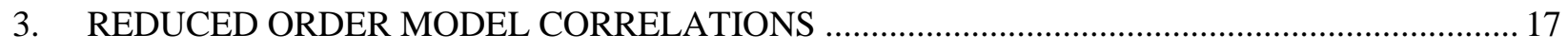

3.1 CALCULATION OF DESIRED OUTPUTS FROM RAW CFD RESULTS ....................... 17

3.2 CONSTRUCTING SURROGATE MODEL USING TASMANIAN .................................... 18

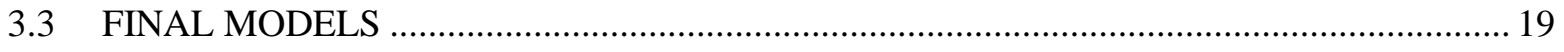

3.3.1 ROM 1: AC unit fan off version \& sample results ................................................. 19

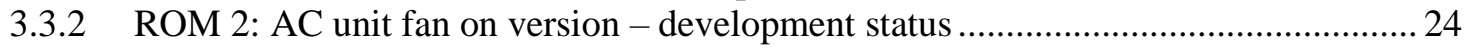

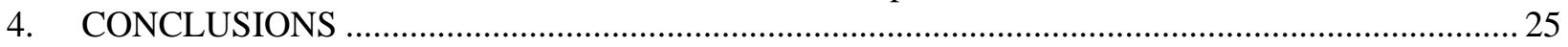

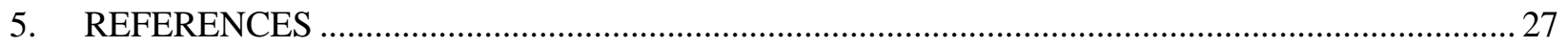

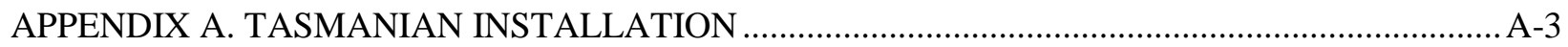

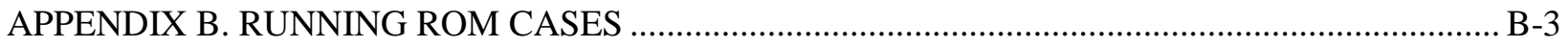




\section{TABLE OF FIGURES}

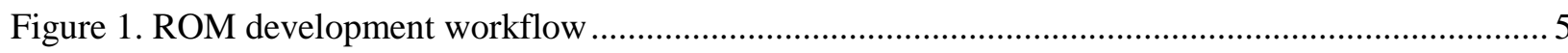

Figure 2. Geometry of room used for ROM CFD simulations. Dimensions shown are for the smallest room floorplan; only one release location shown; doors not shown. 8

Figure 3. Impact of room size on mean refrigerant concentration within the room at specific times in the simulation while other parameters are held constant: unit fan off, door half open, ventilation rate $4.1 \mathrm{~m}^{3} / \mathrm{min}, 7.55 \mathrm{~kg}$ of refrigerant with $\mathrm{MW}=94 \mathrm{~kg} / \mathrm{kmole}$ leaked at $23.43 \mathrm{~kg} / \mathrm{min}$ (19.3 s duration), $1.219 \mathrm{~m}$ above floor.

Figure 4. Range of single room footprints for ROM simulations; (a) smallest ( $5 \mathrm{~m}^{2}$ ), (b) mid-size $\left(10 \mathrm{~m}^{2}\right)$, (c) largest $\left(20 \mathrm{~m}^{2}\right)$ (dimensions in meters; one half of each room shown since designed to be symmetrical to streamline CFD simulations).

Figure 5. Impact of open door area on mean refrigerant concentration within the room while other parameters are held constant: unit fan off, medium-sized room, ventilation rate 4.1 $\mathrm{m}^{3} / \mathrm{min}(144 \mathrm{cfm}), 7.55 \mathrm{~kg}$ of refrigerant with $\mathrm{MW}=94 \mathrm{~kg} / \mathrm{kmole}$ leaked at $23.43 \mathrm{~kg} / \mathrm{min}$ (19.3 $\mathrm{s}$ duration), $1.219 \mathrm{~m}$ above floor.

Figure 6. Locations of leak release, supply and return air diffusers. Note that supply and return diffusers were closed during simulations with the unit fan off.

Figure 7. Impact of leak location height on mean refrigerant concentration within the room while other parameters are held constant: unit fan off, medium-sized room, door half open, ventilation rate $4.1 \mathrm{~m}^{3} / \mathrm{min}(144 \mathrm{cfm}), 7.55 \mathrm{~kg}$ of refrigerant with $\mathrm{MW}=94 \mathrm{~kg} / \mathrm{kmole}$ leaked at $23.43 \mathrm{~kg} / \mathrm{min}(19.3 \mathrm{~s}$ duration).

Figure 8. Impact of ventilation rate on mean refrigerant concentration within the room while other parameters are held constant: unit fan off, medium-sized room, door half open, $7.55 \mathrm{~kg}$ of refrigerant with $\mathrm{MW}=94 \mathrm{~kg} / \mathrm{kmole}$ leaked at $23.43 \mathrm{~kg} / \mathrm{min}$ (19.3 s duration), $1.219 \mathrm{~m}$ above floor...

Figure 9. Impact of ventilation rate on mean refrigerant concentration within the room while other parameters are held constant: unit fan off, small-sized room, door closed, $15 \mathrm{~kg}$ of refrigerant with $\mathrm{MW}=44 \mathrm{~kg} / \mathrm{kmole}$ leaked at $1.875 \mathrm{~kg} / \mathrm{min}$ (480 s duration), $1.822 \mathrm{~m}$ above floor.

Figure 10. Impact of total charge on mean refrigerant concentration within the room while other parameters are held constant: unit fan off, medium-sized room, door half open, ventilation rate $4.1 \mathrm{~m}^{3} / \mathrm{min}$, refrigerant with $\mathrm{MW}=94 \mathrm{~kg} / \mathrm{kmole}$ leaked at $23.43 \mathrm{~kg} / \mathrm{min}$ (0.26-38.4 s duration), $1.219 \mathrm{~m}$ above floor.

Figure 11. Impact of leak rate on mean refrigerant concentration within the room while other parameters are held constant: unit fan off, medium-sized room, door half open, ventilation rate $4.1 \mathrm{~m}^{3} / \mathrm{min}, 7.55 \mathrm{~kg}$ of refrigerant with $\mathrm{MW}=94 \mathrm{~kg} / \mathrm{kmole}$ leaked (3.7$241.6 \mathrm{~s}$ duration), $1.219 \mathrm{~m}$ above floor.

Figure 12. Impact of molecular weight on mean refrigerant concentration within the room while other parameters are held constant: unit fan off, medium-sized room, door half open, ventilation rate $4.1 \mathrm{~m}^{3} / \mathrm{min}, 7.55 \mathrm{~kg}$ of refrigerant leaked at $23.43 \mathrm{~kg} / \mathrm{min}(19.3 \mathrm{~s}$ duration), $1.219 \mathrm{~m}$ above the floor.

Figure 13. Comparison of predicted mean refrigerant concentration with the CFD model (open circles) and ROM (" $\times$ "s) at three test points selected to fall within high sensitivity response regions with limited sampling in CFD training cases (solid dots). Unit fan off, small-sized room, door closed, $15 \mathrm{~kg}$ of refrigerant with $\mathrm{MW}=44 \mathrm{~kg} / \mathrm{kmole}$ leaked at $1.875 \mathrm{~kg} / \mathrm{min}$ (480 s duration), $1.822 \mathrm{~m}$ above floor. 
Figure 14. History of mean refrigerant concentration for different ventilation rates with comparison of CFD (open circle) and ROM ("X"s) predictions at three test points. Unit fan off, small-sized room, door closed, $15 \mathrm{~kg}$ of refrigerant with $\mathrm{MW}=44 \mathrm{~kg} / \mathrm{kmole}$ leaked at $1.875 \mathrm{~kg} / \mathrm{min}$ (480 $\mathrm{s}$ duration), $1.822 \mathrm{~m}$ above floor.

Figure 15. Root mean square error (RMSE) of maximum refrigerant concentration in the room space at different simulation times

Figure 16. Comparison of predicted temporal mean of FVF using CFD model (open circles) and ROM (" $\times$ "s) at three test points falling between training samples (solid dots). Unit fan off, small-sized room, door closed, $15 \mathrm{~kg}$ of refrigerant with $\mathrm{MW}=44 \mathrm{~kg} / \mathrm{kmole}$ leaked at $1.875 \mathrm{~kg} / \mathrm{min}$ (480 $\mathrm{s}$ duration), $1.822 \mathrm{~m}$ above floor.

Figure 17. Comparison of predicted duration with a FVF in the room using CFD model (open circles) and ROM (" $x$ "s) at three test points falling between training samples (solid dots). Unit fan off, small-sized room, door closed, $15 \mathrm{~kg}$ of refrigerant with $\mathrm{MW}=44$ $\mathrm{kg} / \mathrm{kmole}$ leaked at $1.875 \mathrm{~kg} / \mathrm{min}$ (480 s duration), $1.822 \mathrm{~m}$ above floor.

Figure 18. Comparison of predicted FVF at selected times using CFD model (open circles) and ROM (" $\times$ "s) at three test points falling between training samples (solid dots). Unit fan off, small-sized room, door closed, $15 \mathrm{~kg}$ of refrigerant with $\mathrm{MW}=44 \mathrm{~kg} / \mathrm{kmole}$ leaked at $1.875 \mathrm{~kg} / \mathrm{min}$ (480 $\mathrm{s}$ duration), $1.822 \mathrm{~m}$ above floor. 


\section{TABLE OF TABLES}

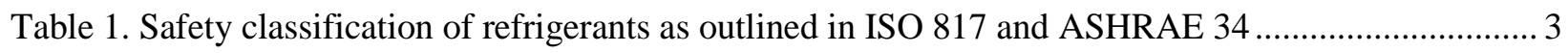

Table 2. CFD simulation setup parameters common to all cases .......................................................... 6

Table 3. Reduced Order Model (ROM) parameters....................................................................... 7

Table 4. Molecular weight (MW), LFL, and UFL for refrigerants used to generate the ROMs................ 17

Table 5. Input parameters for the validation cases. The highlighted cells are values that were not

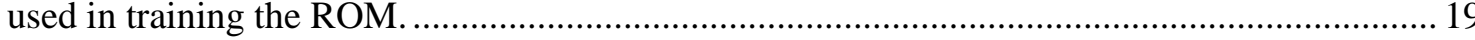




\section{ACKNOWLEDGEMENTS}

The authors gratefully acknowledge the advice and guidance offered over the course of the project by the members of the AHRTI Project Monitoring Subcommittee (PMS) - Jay Kohler (Johnson Controls) chair, Jim Vershaw (Trane), Mary Koban (Chemours), Siva Gopalnarayanan (Rheem), Svend Bennedsen (Danfoss), Rakesh Goel (Lennox), Rusty Tharp (Goodman), Samuel Yana Motta (Honeywell), Randy Cooper (AHAM), Osami Kataoka (Daikin), Xudong Wang (AHRTI), and Antonio Bouza (DOE).

This project was sponsored by the U. S. Department of Energy, Building Technologies Office (DOE/BTO), Antonio Bouza project manager, under Contract No. DE-AC05-00OR22725 with UTBattelle, LLC. 


\section{NOMENCLATURE}

$\mathrm{AC}$

AFV

AHRI

AMR

ASHRAE

BTO

CFD

DLL

DoE

DOE

FVF

GWP

$\mathrm{HC}$

HCFC

HFC

HFO

HVAC\&R

IEC

ISO

LFL

MSDS

MW

ORNL

PISO

PRA

RAC

RMSE

ROM

Tasmanian

UFL

UL
Air Conditioning

Accumulated Fuel Volume

Air-Conditioning, Heating and Refrigeration Institute

Adaptive Mesh Refinement

American Society of Heating, Refrigerating and Air-Conditioning Engineers

Building Technologies Office

Computational Fluid Dynamics

Dynamic-Link Library

Design or Experiments (or Design of Simulation Experiments)

U.S. Department of Energy

Flammable Volume Fraction

Global Warming Potential

Hydrocarbon

Hydrochlorofluorocarbons

Hydrofluorocarbon

Hydrofluoroolefin

Heating, Ventilation, Air Conditioning and Refrigeration

International Electrotechnical Commission

International Standards Organization

Lower Flammability Limit

Material Safety Data Sheet

Molecular Weight

Oak Ridge National Laboratory

Pressure Implicit with Splitting of Operators

Probability Risk Assessment

Room Air Conditioner

Root Means Square Error

Reduced Order Model

Toolkit for Adaptive Stochastic Modeling And Non-Intrusive ApproximatioN

Upper Flammability Limit

Underwriters Laboratories 


\section{EXECUTIVE SUMMARY}

This report provides a detailed description of the development of a reduced order model (ROM) that could be used for estimation of safe charge limits based on a computational fluid dynamics (CFD) parametric study. The ROM was developed to simulate leak events from a single side-wall duct penetration into a room and provide estimates of refrigerant concentration together with flammable volume fraction (FVF), accumulated fuel volume (AFV) and other outputs vs. time.

The ROM is based on a range of seven parameters listed in Table ES1 and assumes that the AC unit air circulation blower is off. A total of 586 CFD "training" cases were run and used as the basis for development and training or calibration of the ROM. The regression analysis used to develop the ROM

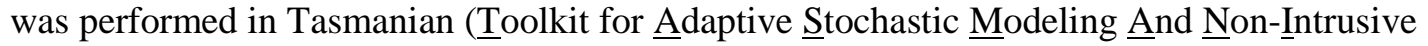
Approximation $)^{1}[1]$. This is a tool developed at ORNL for high-dimensional integration, interpolation and parameter calibration. Comparison of the ROM vs. several CFD test cases (at points not used in the training set) showed maximum absolute and root mean square errors (RMSE) for FVF of $1.32 \%$ and $0.5 \%$, respectively.

Initial CFD runs were conducted to gauge the sensitivity of the results to each parameter. Based on the findings, the numbers of design of experiment (DoE) levels for each parameter was determined. Then, for each parameter, Tasmanian calculated the value of each level and defined a DoE of 586 unique CFD simulation cases.

Table ES1. DoE levels of each parameter.

\begin{tabular}{cccc}
\hline Parameter \# & Parameter & Number of levels & Levels \\
\hline $\mathbf{1}$ & Unit circulation fan & 2 (discrete) & Off, On \\
\hline $\mathbf{2}$ & Room size (floor area) & 3 & $5,10,20 \mathrm{~m}^{2 *}$ \\
\hline $\mathbf{3}$ & Leak release height & 5 & $0,0.616,1.219,1.822,2.438 \mathrm{~m}$ \\
\hline $\mathbf{4}$ & Room openings & 3 & $0.0116,0.988,1.964 \mathrm{~m}^{2}$ \\
\hline $\mathbf{5}$ & Ventilation & 6 & $0,1.0,4.1,8.2,9.2,16.3 \mathrm{~m}^{3} / \mathrm{min}$ \\
\hline $\mathbf{6}$ & Charge amount & 5 & $0.1,3.825,7.55,11.275,15 \mathrm{~kg}$ \\
\hline $\mathbf{7}$ & Leak rate & 5 & $1.875,12.656,23.43,34.219,45 \mathrm{~kg} / \mathrm{min}$ \\
\hline $\mathbf{8}$ & Molecular weight & 5 & $44,69,94,119,144 \mathrm{~kg} / \mathrm{kmole}$ \\
\hline
\end{tabular}

*NOTE: the room floor area here is half the total room size because we used symmetry in the underlying CFD simulations. So, the $5 \mathrm{~m}^{2}-20 \mathrm{~m}^{2}$ area range ROM input actually represents a $10 \mathrm{~m}^{2}-40 \mathrm{~m}^{2}$ room.

All 586 DoE CFD cases were used to train the ROM in Tasmanian. The ROM as presently constituted was designed to provide the following outputs of interest:

- Refrigerant concentration (\% v/v): spatiotemporal maximum and mean across entire room at all times plus min, mean, and max temporal profiles at 5, 10, 20, 50, 100, 200, 300, 400, 500 and 600 seconds

- Flammable volume fraction (FVF, 0-1) and accumulated fuel volume fraction (AFV, 0-1)

$\circ$ FVF is the volume in the room that has a concentration between the lower and upper flammability limits (LFL and UFL) at any time divided by the total volume of the room. FVF is an important input to probability risk assessments (PRA) as an indication of the likelihood of an ignition event.

\footnotetext{
${ }^{1}$ https://tasmanian.ornl.gov/
} 
- $\mathrm{AFV}$ is the volume in the room that has a concentration greater than the LFL at any time divided by the total volume of the room. AFV is an important input to PRAs as an indication of the severity of an ignition event.

- Since CFD used molecular weight as proxy for refrigerant, FVF and AFV were calculated for combinations of LFL and UFL for several flammable refrigerants of interest (see Table 4 in the main report).

- The following statistics are calculated

- Temporal maximum and mean for FVF and AFV

- Total time duration for some FVF and AFV

- FVF and AFV temporal profile at 5, 10, 20, 50, 100, 200, 300, 400, 500 and 600 seconds

After constructing the model, an additional 11 CFD cases, shown in Table ES2, were run to test the resulting ROM.

Table ES2. Input parameters to the test cases. The highlighted cells are values that were not used in training the ROM.

\begin{tabular}{cccccccc}
\hline $\begin{array}{c}\text { Case } \\
\text { number }\end{array}$ & Room & $\begin{array}{c}\text { Leak } \\
\text { elevation } \\
\text { above floor } \\
\mathbf{M}\end{array}$ & Door & Ventilation & Charge & $\begin{array}{c}\text { Leak } \\
\text { rate }\end{array}$ & MW \\
\hline $\mathbf{1}$ & 5 & 1.822 & 0.0116 & 2.8 & 15 & 1.875 & 44 \\
\hline $\mathbf{2}$ & 5 & 1.822 & 0.0116 & 5.7 & 15 & 1.875 & 44 \\
\hline $\mathbf{3}$ & 5 & 1.822 & 0.0116 & 9.9 & 15 & 1.875 & 44 \\
\hline $\mathbf{4}$ & 10 & 1.219 & 0.988 & 4.1 & 7.55 & 23.43 & 57 \\
\hline $\mathbf{5}$ & 10 & 1.219 & 0.988 & 4.1 & 7.55 & 23.43 & 84 \\
\hline $\mathbf{6}$ & 10 & 1.219 & 0.988 & 4.1 & 1 & 23.43 & 94 \\
\hline $\mathbf{7}$ & 10 & 1.219 & 0.988 & 4.1 & 5.5 & 23.43 & 94 \\
\hline $\mathbf{8}$ & 10 & 1.219 & 0.988 & 4.1 & 7.55 & 4 & 94 \\
\hline $\mathbf{9}$ & 10 & 1.219 & 0.988 & 4.1 & 7.55 & 6 & 94 \\
\hline $\mathbf{1 0}$ & 10 & 1.219 & 0.988 & 4.1 & 7.55 & 8 & 94 \\
\hline $\mathbf{1 1}$ & 10 & 1.219 & 0.988 & 4.1 & 7.55 & 28 & 94 \\
\hline
\end{tabular}

For the eleven test cases, the maximum absolute error in the maximum FVF was $1.32 \%$, and the maximum absolute error in the duration of FVF was 205.64 seconds. The root mean square error (RMSE) of those two outputs for the eleven cases were $0.5 \%$ and 77.74 seconds, respectively.

It should be noted that Tasmanian does not produce a closed-form equation of the ROM. It can, however, output a library, e.g. dynamic-link library (DLL), that can be used within other software packages, e.g., MATLAB [2], to calculate the outputs given the inputs. Two appendices to this report (APPENDIX A and APPENDIX B) describe in detail how to install Tasmanian and run the ROM.

A second ROM is in development as well. This ROM will be similar to the ROM described in this report except for the assumption that the AC blower is in operation. A set of 576 CFD simulations is in process. Development of the second ROM will be described in a subsequent publication. 


\section{INTRODUCTION}

Environmental protection goals are becoming progressively stricter to reduce negative global environmental impacts of refrigerants. The Montréal Protocol has required phase-outs of chlorofluorocarbons (CFCs, completed in 2010) and hydrochlorofluorocarbons (HCFCs, expected to be complete by 2030 in developed countries). Hydrofluorocarbons (HFCs) like R-410A and R-134a have been used as alternatives to HCFCs for many HVAC\&R applications but have relatively high global warming potentials (GWP). In October 2016, the Kigali Amendment to the Montréal Protocol was adopted to phase-down the use of HFCs. For developed countries the Kigali Amendment requires HFC consumption to be reduced to $15 \%$ of the average consumption for 2011-2013 by 2036 [3]. Proposed lower-GWP alternatives to replace high-GWP HFCs include hydrocarbons (HC, e.g., propane (R-290)), ammonia (R-717), $\mathrm{CO}_{2}$ (R-744), hydrofluoroolefins (HFO), or blends of low-GWP HFCs with other lowGWP fluids like $\mathrm{CF}_{3} \mathrm{I}$. Most of the viable alternatives are flammable to some degree according to Addendum g to ASHRAE 34-2016 [4] and ISO 817 [5], which designate toxicity and flammability of refrigerants as follows:

Table 1. Safety classification of refrigerants as outlined in ISO 817 and ASHRAE 34

\begin{tabular}{|c|c|c|}
\cline { 2 - 3 } \multicolumn{1}{c|}{} & \multicolumn{2}{c|}{ Safety group } \\
\hline $\begin{array}{c}\text { Higher } \\
\text { flammability }\end{array}$ & $\mathrm{A} 3$ & $\mathrm{~B} 3$ \\
\hline Flammable & $\mathrm{A} 2$ & $\mathrm{~B} 2$ \\
\hline $\begin{array}{c}\text { Lower } \\
\text { flammability }\end{array}$ & $\mathrm{A} 2 \mathrm{~L}^{*}$ & $\mathrm{~B} 2 \mathrm{~L}^{*}$ \\
\hline $\begin{array}{c}\text { No flame } \\
\text { propagation }\end{array}$ & $\mathrm{A} 1$ & $\mathrm{~B} 1$ \\
\hline \multirow{2}{*}{} & $\begin{array}{c}\text { Lower } \\
\text { toxicity }\end{array}$ & $\begin{array}{c}\text { Higher } \\
\text { toxicity }\end{array}$ \\
\cline { 2 - 3 }
\end{tabular}

*A2L and B2L are lower flammability refrigerants with a maximum burning velocity of $\leq 10 \mathrm{~cm} \mathrm{~s}^{-1}$

Refrigerant flammability introduces new challenges to the usage of these refrigerants in real life applications that historically have not been encountered. Those challenges are centered around the deflagration risk associated with using flammable material and its implications for personal safety. Standards have been developed to systematically set maximum allowable refrigerant charges to ensure safety in case of refrigerant leakage. These standards were based on numerical analyses of refrigerant leakage into confined spaces as well as risk analyses of associated ignition events. Currently published standards include the International Electrotechnical Commission (IEC) standard IEC 60335-2-40 [6], Underwriter's Laboratories (UL) 60335-2-40 [7], International Standards Organization (ISO) 5149 [8], ASHRAE 15 [9], UL 471 [10], UL 60335-2-24 [11], UL 60335-2-89 [12], UL 563 [13], etc.

While expanded use of the low-GWP refrigerants noted above is generally seen as a key to reducing the global environmental impact of HVAC\&R equipment and systems, current codes significantly restrict the use of all flammable refrigerants (including lower-flammability A2L types). Since A2L refrigerants are treated at the same risk level as those in the A2 category in many standards and in some cases, there is no discrimination between any level of flammability. Therefore, there is a need to revise the relevant safety standards and codes to facilitate wider use of flammable low-GWP refrigerant alternatives; especially A2L refrigerants. However, the bodies responsible for maintaining and updating these standards and codes must have credible, publicly available, science-based knowledge about the safe use of these refrigerants. In particular, information is needed to enable credible estimates of safe charge limits for the 
different flammable refrigerant options for different HVAC\&R applications. Currently, there are significant gaps in this information.

Recognizing this global challenge, the Alliance for Responsible Atmospheric Policy, the AirConditioning Heating and Refrigeration Institute (AHRI), ASHRAE, the U.S. Department of Energy (DOE), and the State of California began coordination to develop an effective and efficient program to facilitate development of this information. In 2016, these groups agreed to commit $\$ 5.8$ million (M) to cover the highest-priority research needs: AHRI ( $\$ 1 \mathrm{M})$, ASHRAE ( $\$ 1.3 \mathrm{M}), \mathrm{DOE}(\$ 3.0 \mathrm{M})$, and the State of California (\$0.5 M). In 2016, Oak Ridge National Laboratory (ORNL) began a project under this collaboration to investigate a systematic approach to setting safe charge size limits for various types of equipment employing flammable refrigerants. The primary objective of the project is to examine the currently imposed charge limits for flammable refrigerant (A2L, A2, and A3) and identify reasonable adjustments to these limits as appropriate.

This report is the second of two describing the scope, tasks, and relevant results of the project. The first volume [14] summarized results of a stakeholders' workshop and a current and prior literature review. A discussion of the initial computational fluid dynamics (CFD) studies together with companion calibration tests and model validation results was also included together with key results from CFD simulations of a representative 4-room single-family house and duct system, and of a single room with small room air conditioner (RAC). Finally, the initial development work on a Reduced Order Model (ROM) was discussed.

This volume provides a detailed description of the ROM development. The ROMs are intended to be simple tool that can provide quick estimate of safe charge limits based on a CFD parametric study. The study focus is on refrigerant releases in a single room for a range of parameters including refrigerant, refrigerant release rate, quantity, release height, outdoor air ventilation rate, and room floor area. Two ROM versions are discussed: one with no room air circulation (air conditioner blower off) and one with circulation. The fan "off" ROM is the primary subject of this report. Fan "on" ROM development will be the subject of a subsequent publication. 


\section{REDUCED ORDER MODEL DEVELOPMENT APPROACH}

The final stage of this project consists of completing a series of CFD single-room simulations to support formulation of a reduced order model or ROM. The ROM is a multi-dimensional response fit of any of the CFD outputs to any number of the input variables. For any CFD output of interest, a ROM could be fitted or "trained" to correlate it to any number of independent variables. Figure 1 shows the overall approach of ROM development.

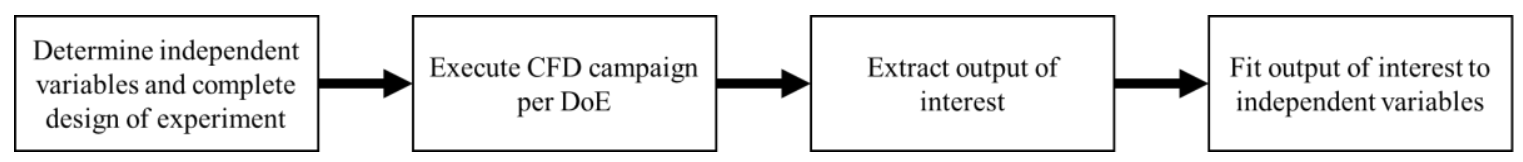

Figure 1. ROM development workflow

As described within this report, the subject ROM does not directly output the safe charge limit for a certain case. Rather, it has been formulated based on the underlying CFD simulation results to enable prediction of outputs that could be used to determine a safe charge limit for a refrigerant with its LFL and UFL concentration range. For example, the ROM has been "trained" to predict the maximum concentration in the room given certain operating conditions. If the criterion of safe charge is to limit the maximum concentration to below the LFL, then the ROM can be used to verify whether the charge is safe.

\subsection{CFD SIMULATION CAMPAIGNS}

For this study, efforts were focused on simulation of a refrigerant leak in the vapor phase from a single side-wall duct penetration into a room. An initial analysis was performed to determine the key parameters required to fully describe possible behaviors for this scenario. A sparse grids sampling approach [15] was then used to develop a design of experiments (DoE) with a minimum number of required cases to accurately cover the parameter space. CFD simulations were performed to provide the base data for construction of the ROM.

\subsubsection{Overview of CFD model}

The commercial software platform CONVERGE 2.3.17 [16] was used for the CFD simulation. The geometry models for the simulation domain were built in SolidWorks ${ }^{\mathrm{TM}}$ [17] and then exported to CONVERGE STUDIO to set up the CFD model. To reduce computational requirements, the cases were set up to take advantage of symmetry so that only half the domain needed to be modeled. Common simulation parameters used for all simulated cases are listed in Table 2. The CONVERGE adaptive mesh refinement (AMR) tool was used on these runs to allow use of a coarser base grid which is only refined in areas where high sub-grid property gradients are predicted. Specifically, a cubic base grid of $0.1 \mathrm{~m}$ was used to model the three room sizes, resulting in base mesh sizes of approximately 14,000,30,000, and 54,000 cells. AMR sub-grid tolerances are set to $1 \mathrm{~m} / \mathrm{s}$ for velocity and $0.5 \%$ for mass fraction of refrigerant with a minimum grid size of $0.0125 \mathrm{~m}$. If the velocity or refrigerant concentration are predicted to vary across a cell by more than the specified tolerance, CONVERGE will automatically subdivide that cell into smaller cells until either the sub-grid tolerances are no longer exceeded, or the minimum cell size is reached. This approach provides a more accurate tracking of the mixing front with less numerical diffusion than the coarse mesh alone and less computational requirements than a refined mesh across the full domain. 
Table 2. CFD simulation setup parameters common to all cases

\begin{tabular}{lc}
\hline Equation of state & Ideal gas \\
\hline Solver & Transient \\
\hline Gas Flow Solver & Compressible \\
\hline Body Force $\left(\mathbf{m} / \mathbf{s}^{\mathbf{2}}\right)$ & 9.81 \\
\hline Turbulence Model & Standard $k-\varepsilon$ \\
\hline Pressure-Velocity Coupling & Pressure implicit with splitting of operators (PISO) \\
\hline Initial Time Step (s) & $1 \mathrm{e}-05$ \\
\hline Minimum Time Step (s) & $1 \mathrm{e}-07$ \\
\hline Maximum Time Step (s) & 0.5 \\
\hline Total Simulation Time (s) & 600 \\
\hline
\end{tabular}

\subsubsection{Parameter domain}

For the scenario in this study with refrigerant leaked as a vapor from a single side-wall duct penetration into a room, the following eight independent variables were assumed to fully describe the evolution of the temporal and spatial dispersion of leaked refrigerant into the room:

- Air circulation (on/off),

- Room size (volume),

- Leak release height,

- Room openings,

- Ventilation rate,

- Charge amount,

- Leak rate,

- Refrigerant molecular weight.

The DoE and the regression analysis were performed in Tasmanian (Toolkit for Adaptive $\underline{\text { Stochastic }}$ Modeling And Non-Intrusive ApproximatioN) ${ }^{2}$ [1], a tool developed at ORNL for high-dimensional integration, interpolation and parameter calibration. In constructing the DoE, the range of each parameter was chosen to exceed the expected range of interest to allow interpolation within instead of extrapolation outside of the training domain. Learnings from previous simulation efforts [14] and results from a small subset of initial simulations were used obtain an estimate of the sensitivity and functionality of the model response (as indicated by mean refrigerant concentration in the room) to each input parameter. This information was used with the sparse grids sampling tools within Tasmanian to determine the required number of sample points for each parameter as well as the functionality of the fit. For example, fewer sample points are needed to describe a linear response to changes in the input parameter than to describe asymptotic or other highly nonlinear responses. Table 3 summarizes the range and number of levels chosen for each parameter with additional detail provided below. The resulting DoE contained 586 cases for the "fan off" ROM.

\footnotetext{
${ }^{2}$ https://tasmanian.ornl.gov/
} 
Table 3. Reduced Order Model (ROM) parameters

\begin{tabular}{cccc}
\hline Parameter \# & Parameter & Number of levels & Levels \\
\hline $\mathbf{1}$ & Unit circulation fan & 2 (discrete) & Off, On \\
\hline $\mathbf{2}$ & Room floorplan area & 3 & $5,10,20 \mathrm{~m}^{2 *}$ \\
\hline $\mathbf{3}$ & Leak release height & 5 & $0,0.616,1.219,1.822,2.438 \mathrm{~m}$ \\
\hline $\mathbf{4}$ & Room openings & 3 & $0.0116,0.988,1.964 \mathrm{~m}^{2}$ \\
\hline $\mathbf{5}$ & Ventilation & 6 & $0,1.0,4.1,8.2,9.2,16.3 \mathrm{~m}^{3} / \mathrm{min}$ \\
\hline $\mathbf{6}$ & Charge amount & 5 & $0.1,3.825,7.55,11.275,15 \mathrm{~kg}$ \\
\hline $\mathbf{7}$ & Leak rate & 5 & $1.875,12.656,23.43,34.219,45 \mathrm{~kg} / \mathrm{min}$ \\
\hline $\mathbf{8}$ & Molecular weight & 5 & $44,69,94,119,144 \mathrm{~kg} / \mathrm{kmole}$ \\
\hline
\end{tabular}

*NOTE: the room floor area here is half the total room size because we used symmetry in the underlying CFD simulations. So, the $5 \mathrm{~m}^{2}-20 \mathrm{~m}^{2}$ area range ROM input actually represents a $10 \mathrm{~m}^{2}-40 \mathrm{~m}^{2}$ room.

Air circulation is a discrete parameter describing whether the unit fan is on or off during the leak. The state of the unit fan during the leak has an extreme impact on how the refrigerant enters, mixes within, and is dispersed from the room. With the unit fan on, the leaked refrigerant is more readily mixed with the circulating air and more widely distributed throughout the room. With the unit fan off, mixing and distribution is more heavily dependent on leak rate. Low leak rates produce less mixing and higher localized refrigerant concentrations as the refrigerant cascades into the room and collects along the floor. Under these conditions, the state of room openings (doors) has a much greater contribution to refrigerant leaving the room than ventilation. At higher leak rates, the refrigerant enters as a plume, entraining and mixing with air, resulting in more uniform dispersion throughout the room and lower local concentrations. In these conditions, room openings and ventilation both contribute significantly to removal of refrigerant from the room. Due to the discrete nature of this parameter and the extreme impact it has on dispersion of the refrigerant, it was decided that separate ROMs would be needed for the "fan on" and "fan off" cases. This report primarily focuses on the "fan off" case, which has the lesser amount of mixing and consequently higher likelihood of exceeding the LFL. The room used as the basis for the CFD simulations had a floorplan aspect ratio of 3:4 and a height of $2.44 \mathrm{~m}(8 \mathrm{ft})$ as shown in Figure 2. A symmetric room design was chosen to reduce computational demands by only simulating half of the room (the green shaded area in Figure 2 represents the plane of symmetry). The floorplan area (and thus total room volume) was varied as one of the model parameters.

Figure 3 provides results from the initial parametric sensitivity study in which CFD simulations were performed with floorplan area varied while all other parameters were held constant. The colored open circles represent the mean refrigerant concentration in the room computed by the CFD model. Different colors represent different elapsed times since the start of the leak event (time in $\mathrm{s}$ as labeled on the $\mathrm{z}$-axis). In this and subsequent similar plots, each line connecting the open circles represents the response of an output variable (in this case, average refrigerant concentration at specified time) to changes in the input variable (in this case, floor area). At the parameter conditions specified for Figure 3 simulations, the refrigerant enters as a plume and mixes well with room air. While the leak is active (for the first $20 \mathrm{~s}$ of simulation time in this case), mean concentrations are higher for the smaller rooms as expected. The functionality also follows expected trends, reducing along a $2^{\text {nd }}$-order response with floorplan area. Once the full charge has leaked into the room, the refrigerant quickly exits through the door opening and ventilation fan. The smaller rooms are evacuated more quickly resulting in a brief period where the average concentration is higher in the larger room (c.f., the 50s and 100 s points for the $20 \mathrm{~m}^{2}$ room). Based on these results, three different floor areas $\left(5,10\right.$, and $\left.20 \mathrm{~m}^{2}\right)$ in the DoE were deemed sufficient to capture the sensitivity and functionality of the observed response. Note that for this and most of the other similar figures in this section that the major transient is effectively over by the 100 s point in the 
simulation. Three separate geometry models for the CFD simulations were created to represent the changing simulation domain as shown in Figure 4.

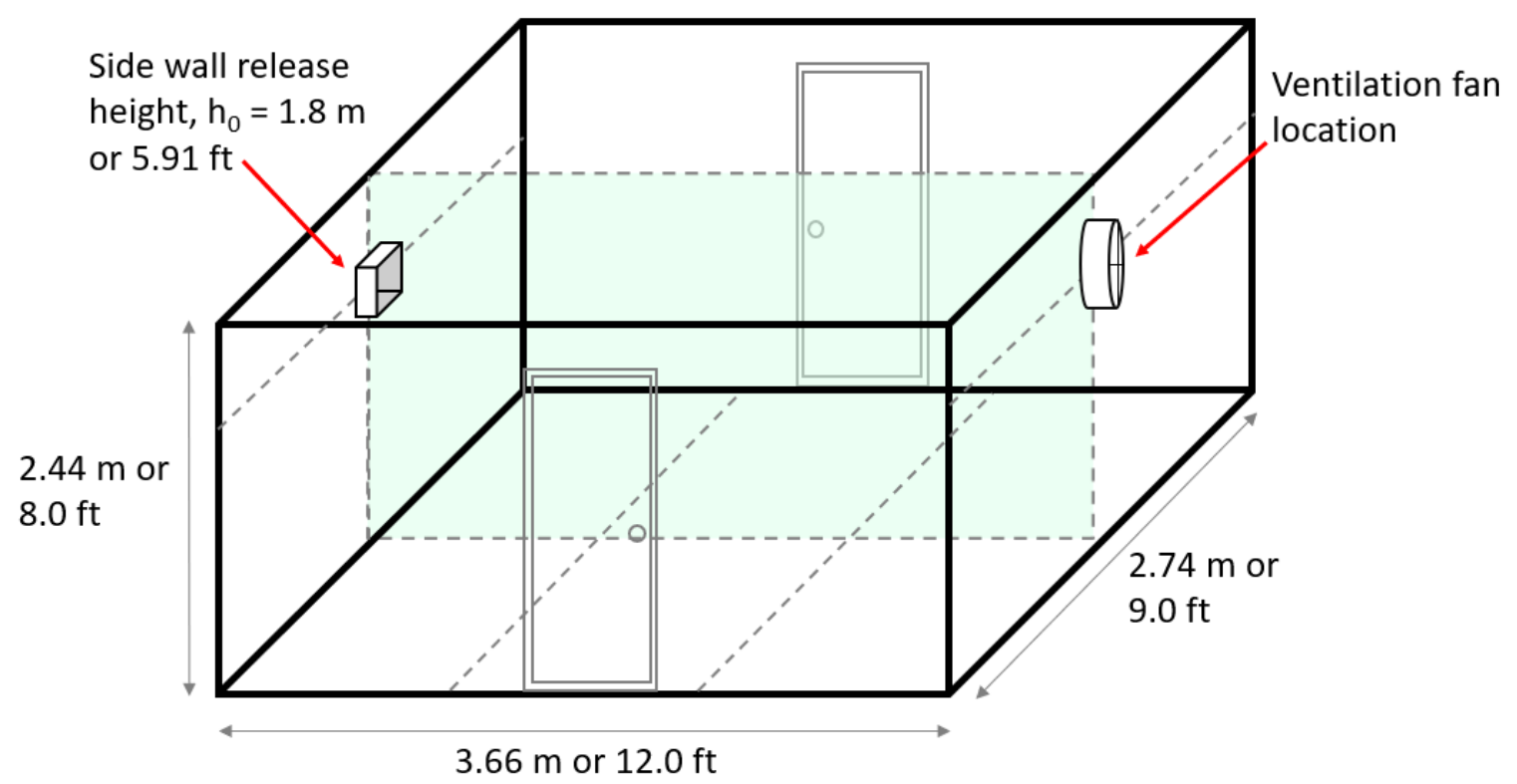

Figure 2. Geometry of room used for ROM CFD simulations. Dimensions shown are for the smallest room floorplan; only one release location shown.

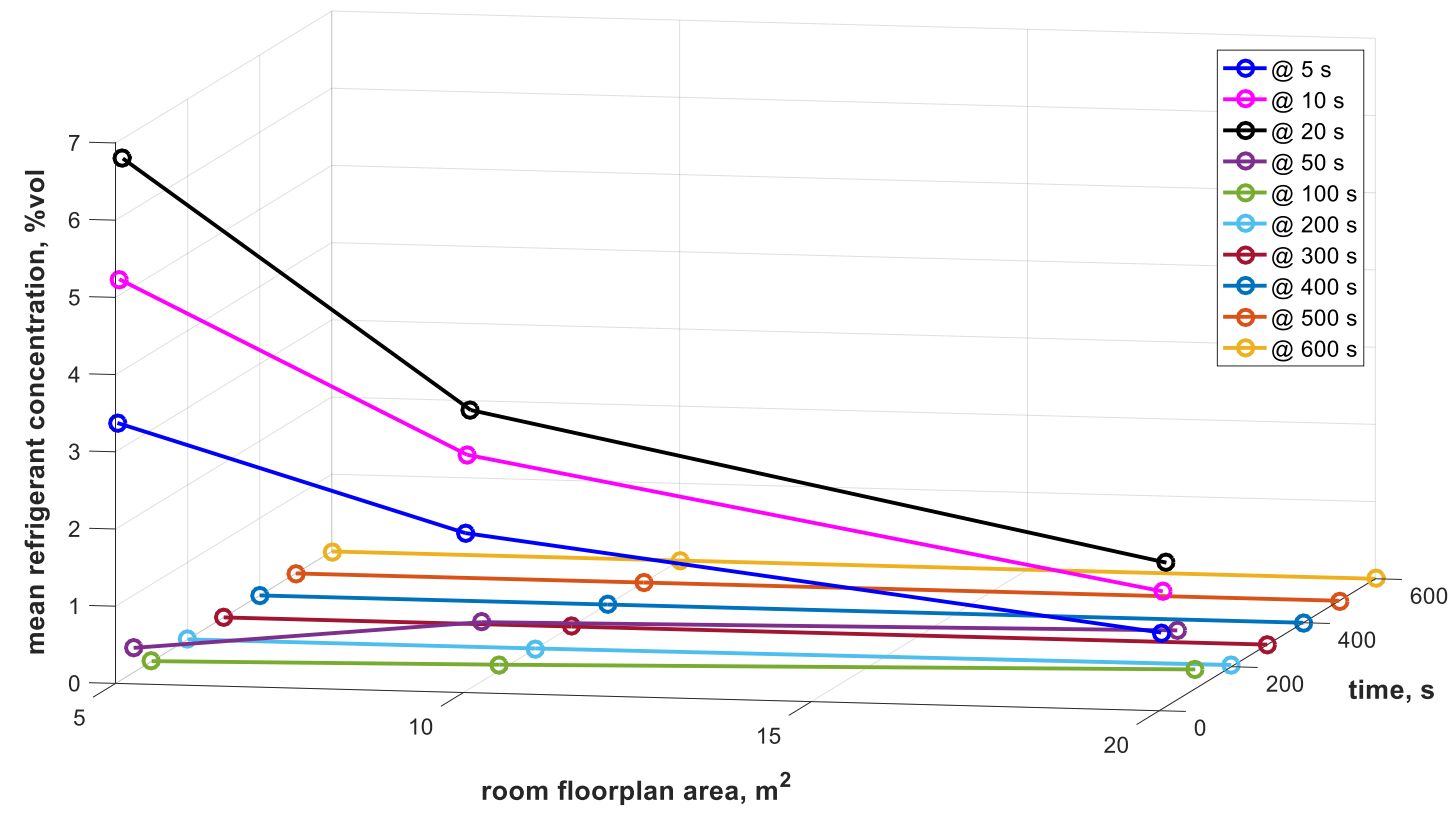

Figure 3. Impact of room size on mean refrigerant concentration within the room at specific times in the simulation while other parameters are held constant: unit fan off, door half open, ventilation rate $4.1 \mathrm{~m}^{3} / \mathrm{min}$, $7.55 \mathrm{~kg}$ of refrigerant with $\mathrm{MW}=94 \mathrm{~kg} / \mathrm{kmole}$ leaked at $23.43 \mathrm{~kg} / \mathrm{min}$ (19.3 s duration), $1.219 \mathrm{~m}$ above floor. 


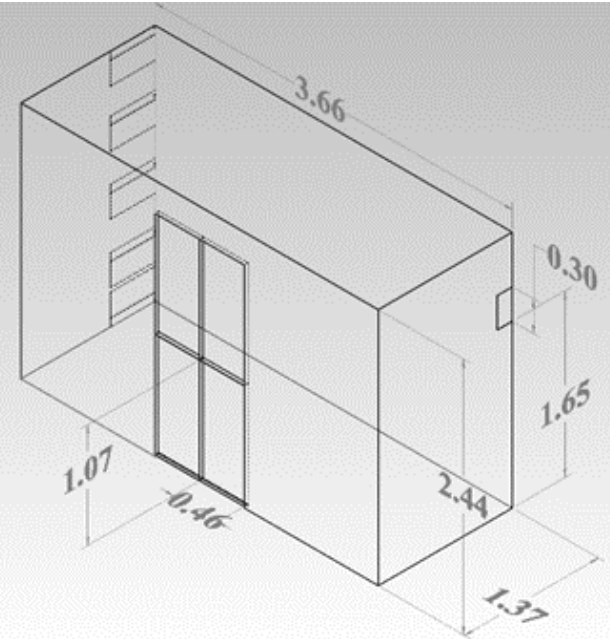

(a.)

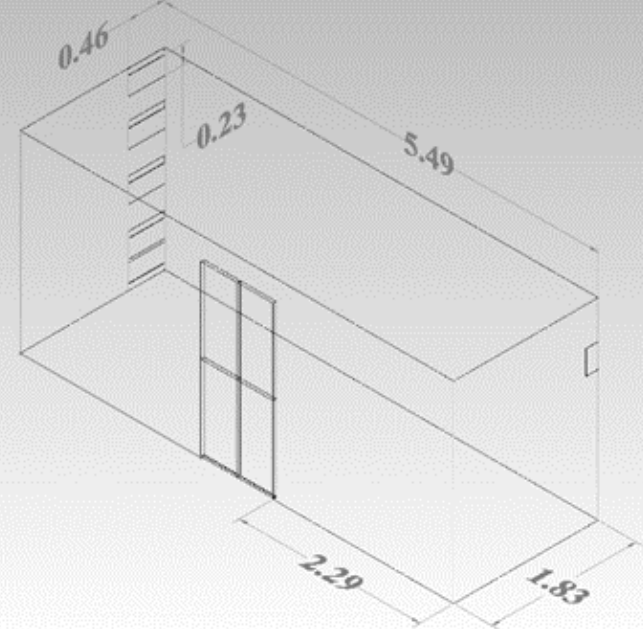

(b.)

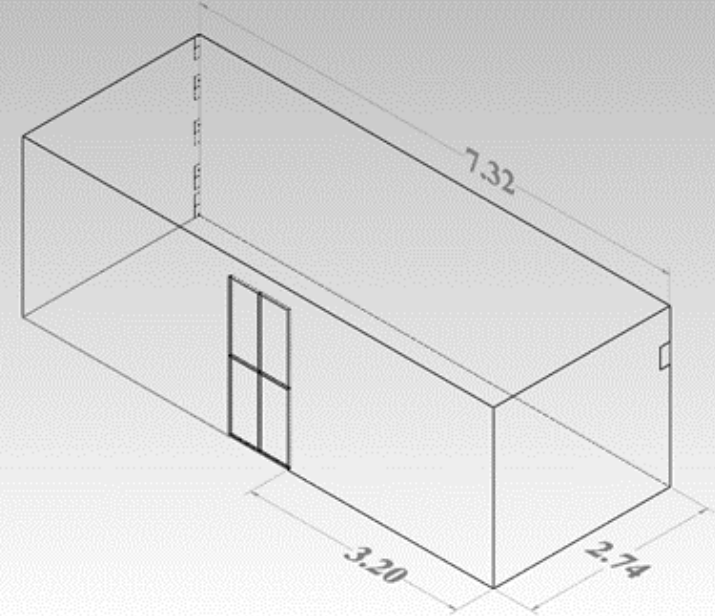

(c.)

Figure 4. Range of single room footprints for ROM simulations; (a) smallest $\left(5 \mathrm{~m}^{2}\right)$, (b) mid-size (10 $\left.\mathrm{m}^{2}\right)$, (c) largest $\left(\mathbf{2 0} \mathrm{m}^{2}\right)$, dimensions in meters, one half of each room shown 
Room openings included two doors located in the center of each long $(3.66 \mathrm{~m})$ side wall to maintain symmetry (see Figure 2). It was assumed that both doors were open by the same amount, again to maintain simulation symmetry. Sensitivity of mean refrigerant concentration to open door area is shown in Figure 5. During the leak (first 20s of simulation), very little sensitivity to open door area is noted. However, once the leak has stopped, the refrigerant disperses from the room through the doors very quickly when half or fully open but much more slowly when closed. This results in a higher-order functionality at the longer simulation times. Based on these results, three conditions were included in the DoE: door closed with small air gap at bottom $\left(0.0116 \mathrm{~m}^{2}\right.$ opening), door half open $\left(0.988 \mathrm{~m}^{2}\right)$, and door fully open $\left(1.964 \mathrm{~m}^{2}\right)$. In the CFD geometry model, the door was represented by three surfaces which could be treated as either wall or outflow (with backflow) boundaries. A higher-order functionality was assumed for this parameter but additional refinement by adding more sample points at the low end of the input parameter space (e.g., more points for open door areas between "closed" and "half open") would likely result in improved accuracy.

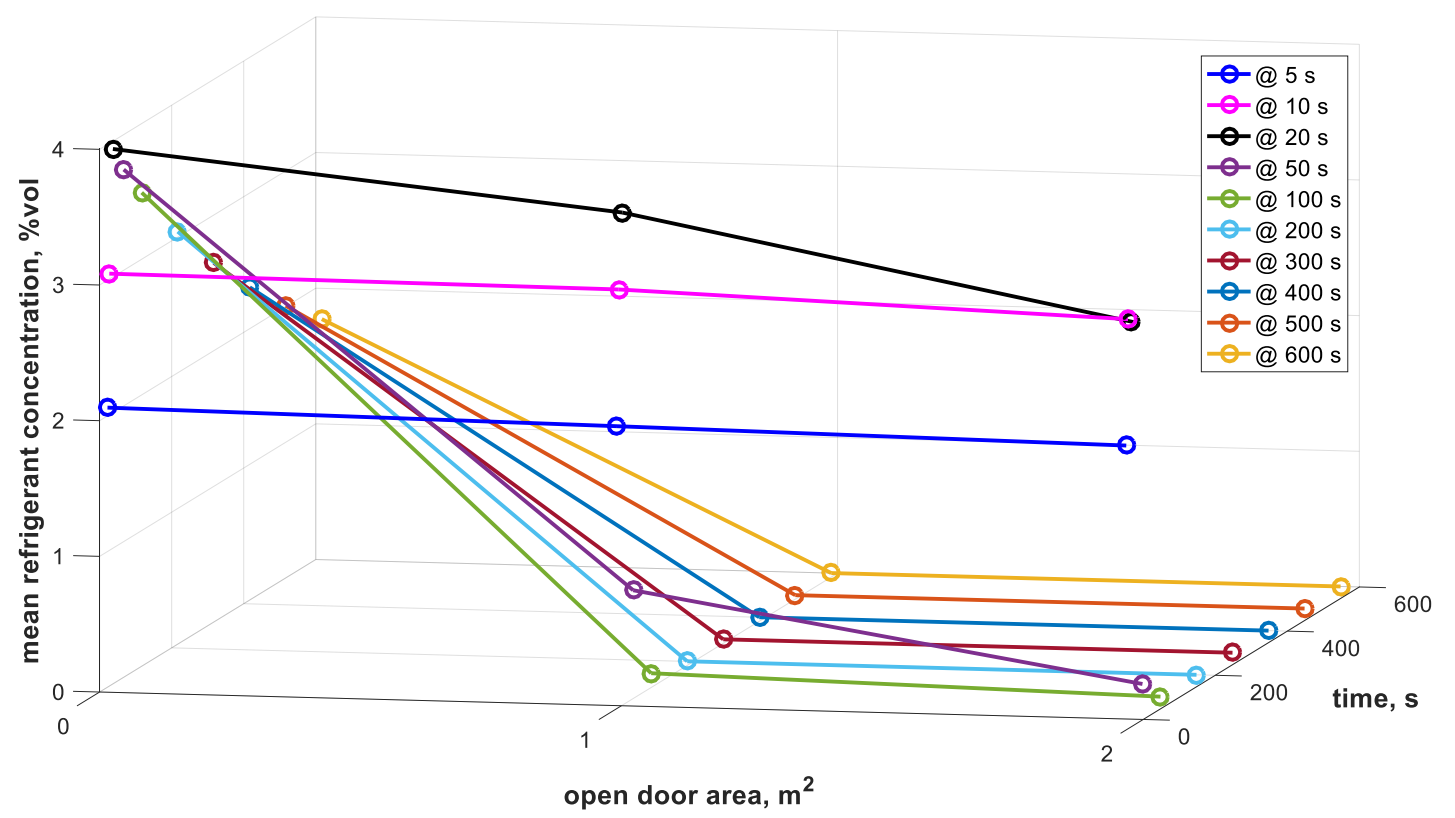

Figure 5. Impact of open door area on mean refrigerant concentration within the room while other

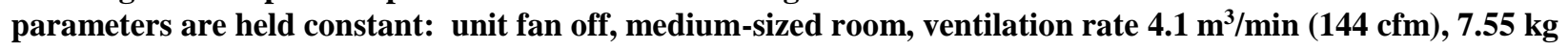
of refrigerant with $M W=94 \mathrm{~kg} / \mathrm{kmole}$ leaked at $23.43 \mathrm{~kg} / \mathrm{min}(19.3 \mathrm{~s}$ duration), $1.219 \mathrm{~m}$ above floor.

Release height of the leak spanned from $0 \mathrm{~m}$ (floor leak) to $2.44 \mathrm{~m}$ (ceiling leak). As shown in Figure 6, unit location was placed at the midpoint of one of the short walls along the line of symmetry. The leaked refrigerant was introduced through a $6.45 \mathrm{~cm}^{2}$ (1 in $\mathrm{x} 1$ in) area which was represented in the CFD model by a $3.225 \mathrm{~cm}^{2}$ ( 1 in $x 0.5 \mathrm{in}$ ) inflow boundary accounting for symmetry. This approach was developed during previous validation efforts comparing CFD predictions with experimental observations [14]. The supply and return grills for the unit were represented as shown in Figure 6, but for the "fan off" cases, these were closed and set as wall boundaries in the CFD model. As shown in Figure 7, sensitivity to leak location (i.e., elevation above floor) increases greatly near the floor and ceiling during the leak. Based on this observation, a total of five leak height locations were considered in the DoE. In addition to the minimum, maximum, and mid-point heights, two additional leak heights $(0.616$ and $1.822 \mathrm{~m})$ were chosen to represent typical unit installation locations. 


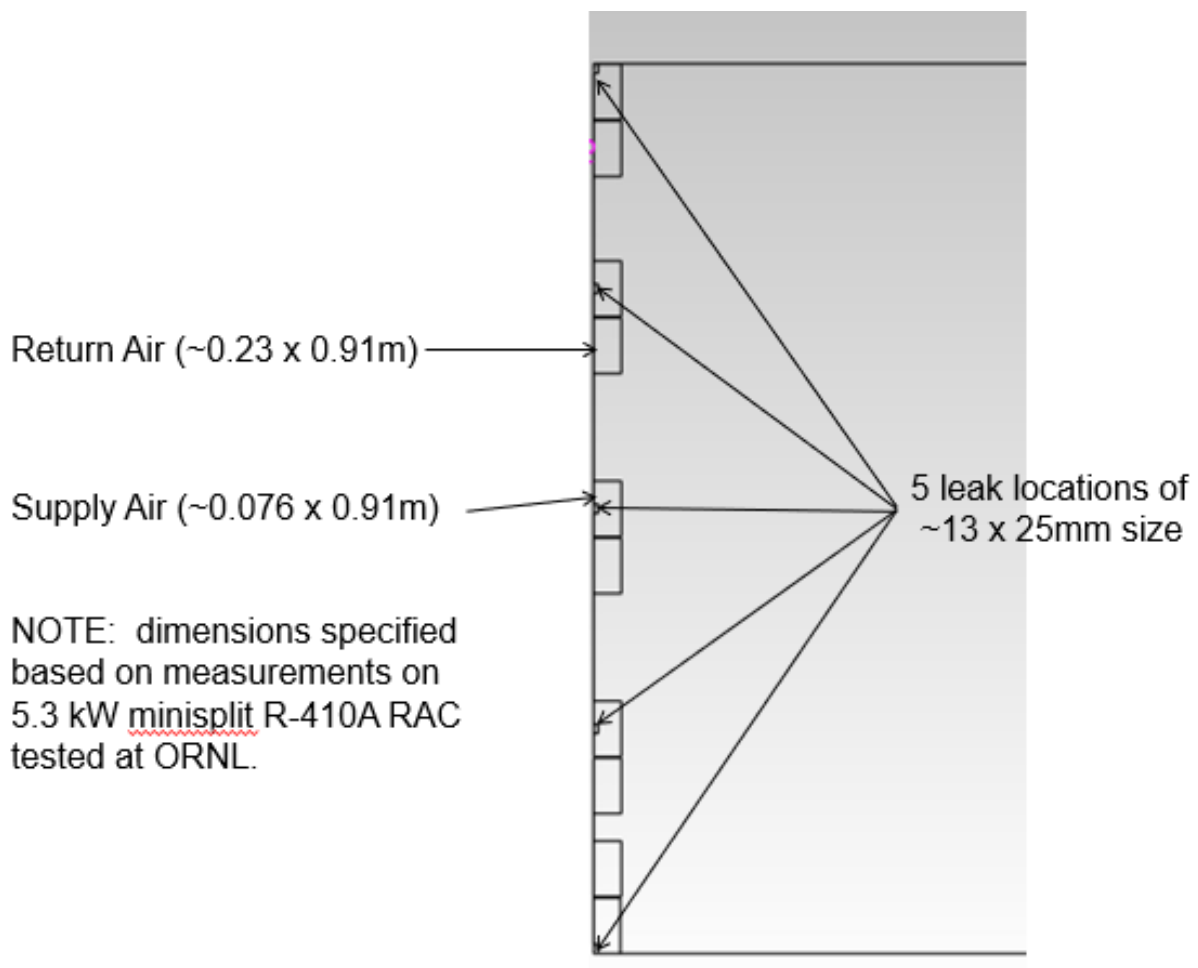

Figure 6. Elevation view showing locations of leak release, supply and return air diffusers. Note that supply and return diffusers were closed during simulations with the unit fan off.

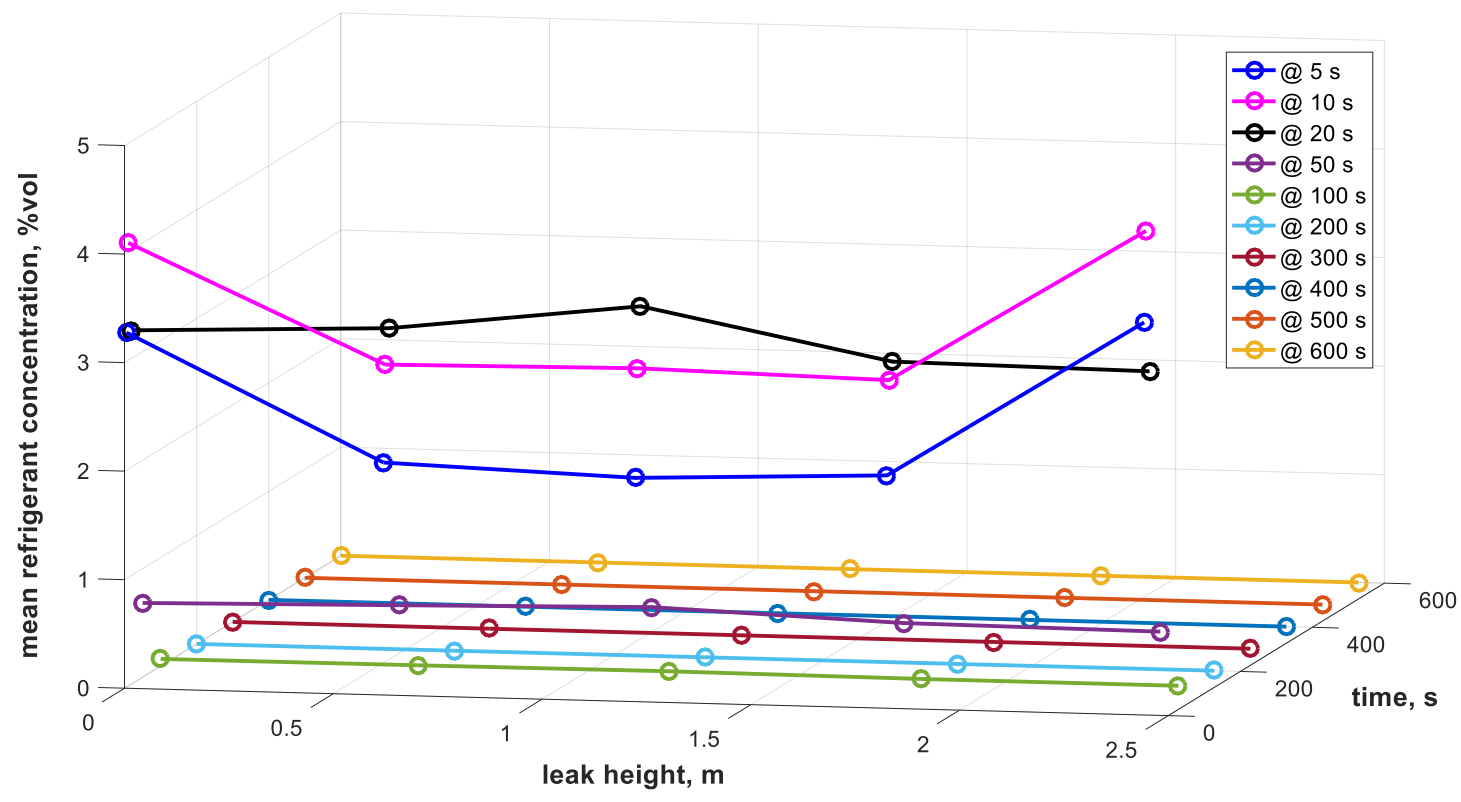

Figure 7. Impact of leak location height on mean refrigerant concentration within the room while other parameters are held constant: unit fan off, medium-sized room, door half open, ventilation $\mathrm{rate}^{4.1} \mathrm{~m}^{3} / \mathrm{min}$ $(144 \mathrm{cfm}), 7.55 \mathrm{~kg}$ of refrigerant with $\mathrm{MW}=94 \mathrm{~kg} / \mathrm{kmole}$ leaked at $23.43 \mathrm{~kg} / \mathrm{min}(19.3 \mathrm{~s}$ duration). 
Room ventilation is supplied by a fan located $1.8 \mathrm{~m}$ above the floor along the wall opposite the leak. In the CFD model it is represented by a $0.305 \mathrm{~m}$ x $0.305 \mathrm{~m}$ (or $0.152 \mathrm{~m}$ with symmetry) outflow boundary with an imposed average velocity. The parameter range was chosen to vary from 0 to $16.3 \mathrm{~m} / 3 / \mathrm{min}(576$ $\mathrm{cfm})$. The maximum ventilation rate was chosen to provide ten turnovers of room air per hour for the large room. In the CFD model, the ventilation rate was specified as an average velocity across the ventilation fan boundary ranging from 0 to $2.926 \mathrm{~m} / \mathrm{s}$ accounting for symmetry. The sensitivity study found that model response to ventilation rate is dependent upon open door area. With the door partially or fully open, most refrigerant quickly leaves the room through the door (as shown in Figure 5), and the mean refrigerant concentration in the room has very low sensitivity to ventilation rate as seen in Figure 8 . But with the door closed, the response is reverse-sigmoidal (Z-shaped) with highest sensitivity at the low end of the considered ventilation range as seen in Figure 9. For the DoE, a high-order functionality and six values were chosen with distribution of sample points skewed toward lower ventilation rates where sensitivity is higher.

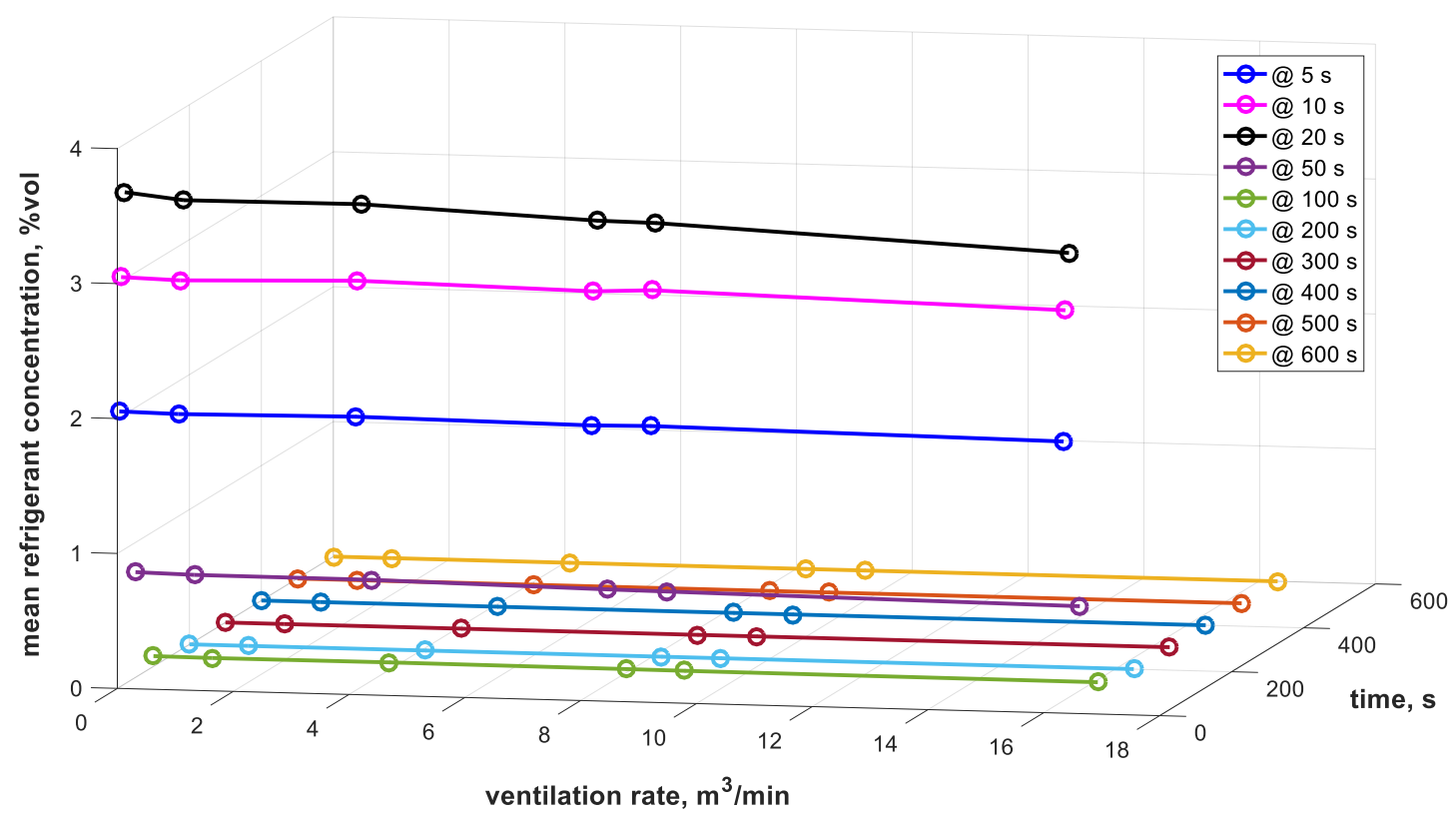

Figure 8. Impact of ventilation rate on mean refrigerant concentration within the room while other parameters are held constant: unit fan off, medium-sized room, door half open, $7.55 \mathrm{~kg}$ of refrigerant with $M W=94 \mathrm{~kg} / \mathrm{kmole}$ leaked at $23.43 \mathrm{~kg} / \mathrm{min}$ (19.3 $\mathrm{s}$ duration), $1.219 \mathrm{~m}$ above floor. 


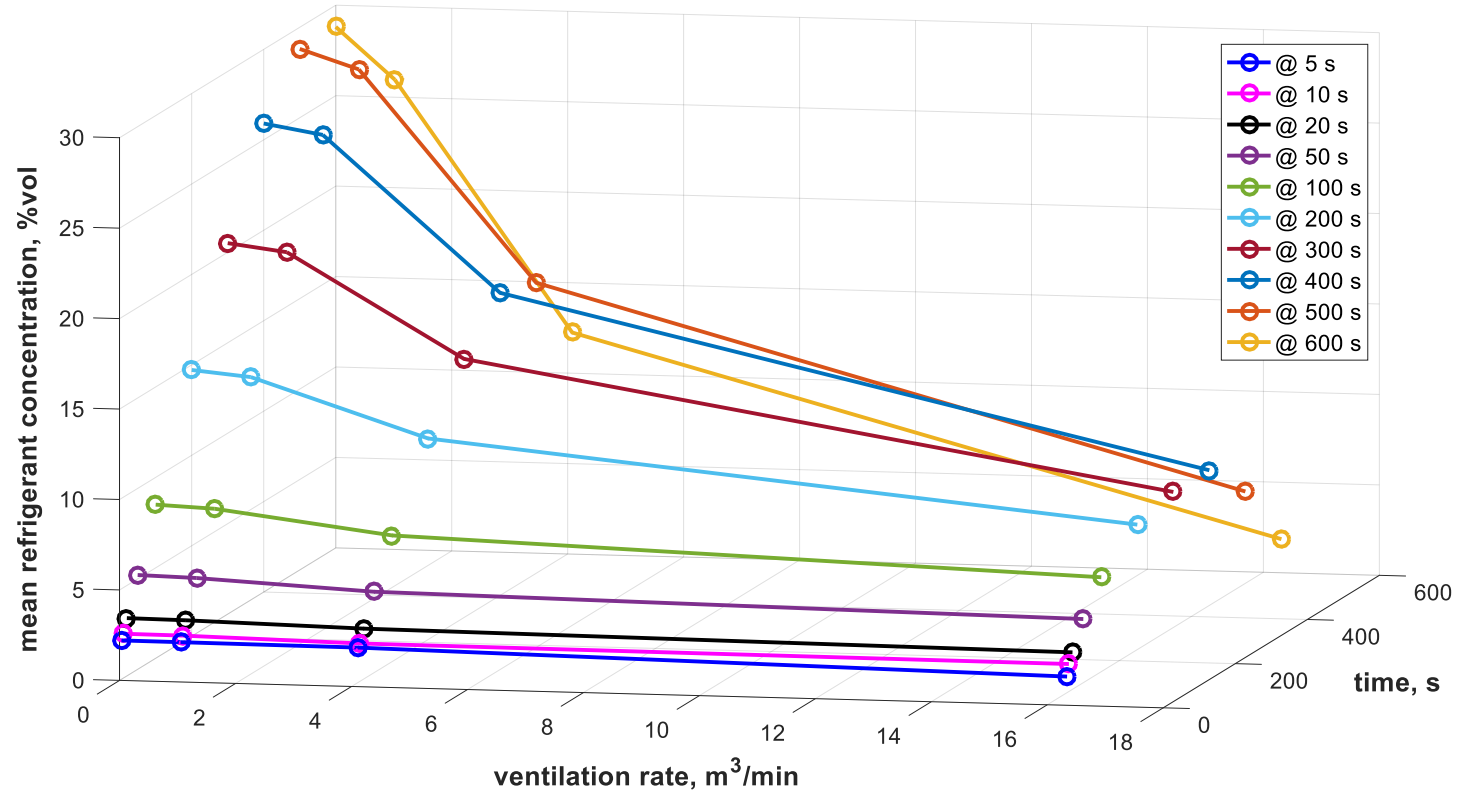

Figure 9. Impact of ventilation rate on mean refrigerant concentration within the room while other parameters are held constant: unit fan off, small-sized room, door closed, $15 \mathrm{~kg}$ of refrigerant with MW=44 $\mathrm{kg} / \mathrm{kmole} \mathrm{leaked} \mathrm{at} 1.875 \mathrm{~kg} / \mathrm{min}$ (480 s duration), $1.822 \mathrm{~m}$ above floor.

maximum refrigerant charge, $\mathrm{m}_{\max }$, for a given scenario depends upon the release height, floor plan area, and refrigerant properties as specified by IEC 60335-2-40 [18] . The range of possible $m_{\max }$ values due to all possible combinations of the release height and floor plan area parameter ranges in this study (Table 3), and considering refrigerants ranging from R-290 to R-454C (LFL range 0.038 to $0.460 \mathrm{~kg} / \mathrm{m}^{3}$ per ASHRAE 34-2016 [3]) was determined to be 0.15 to $\sim 10.3 \mathrm{~kg}$. Based on this information, a range of 0.1 to $15 \mathrm{~kg}$ was chosen for the total charge parameter to ensure the expected range of $\mathrm{m}_{\max }$ was covered with some high-side allowance for potential future flammable charge limit increases. For the CFD simulations, the total charge was cut in half to account for symmetry. The sensitivity study indicated an asymptotic response to changes in total charge as seen in Figure 10. Therefore, five values of total charge, evenly spaced over the parameter range, were used in the DoE to account for the high sensitivity and higher-order functionality. 


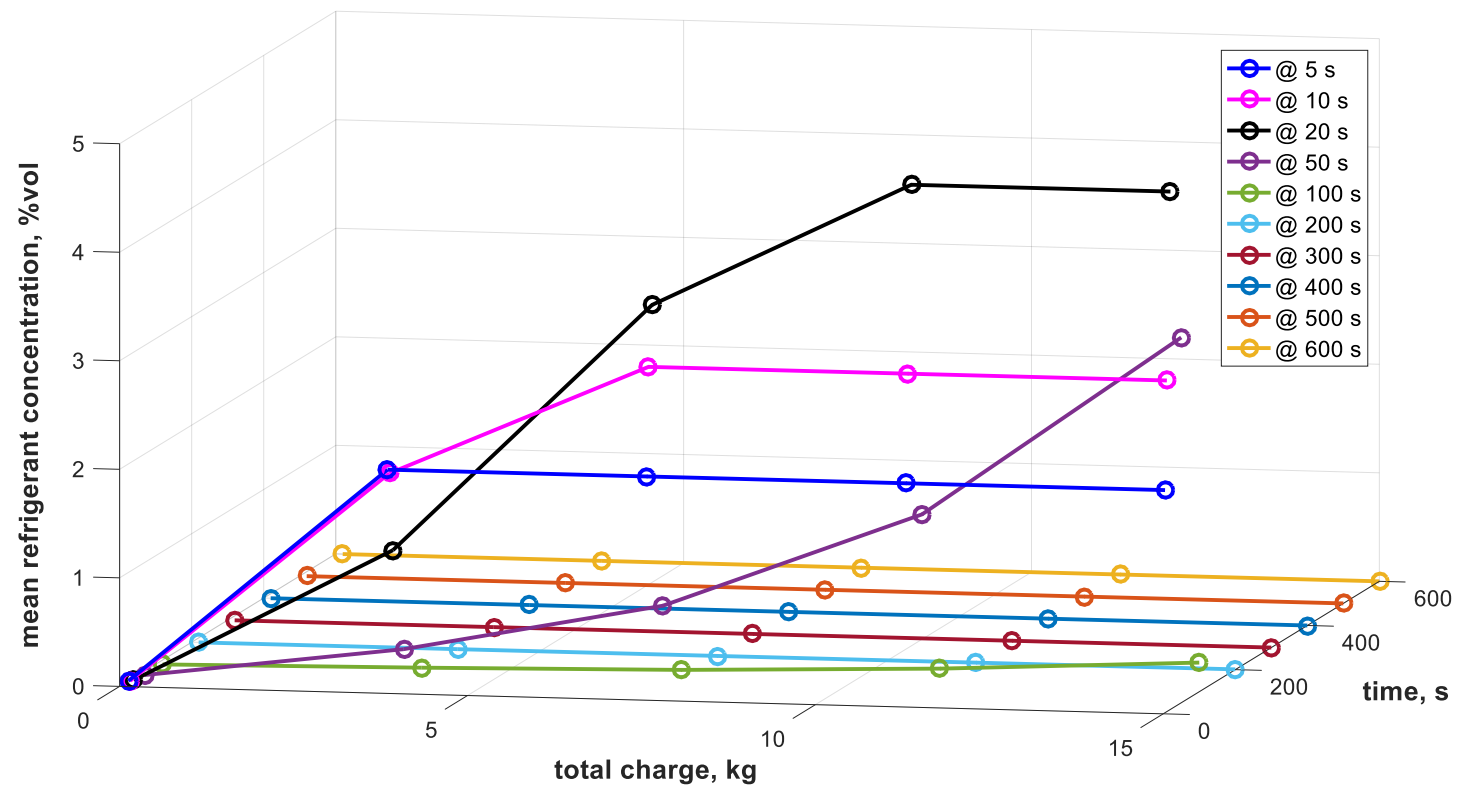

Figure 10. Impact of total charge on mean refrigerant concentration within the room while other parameters are held constant: unit fan off, medium-sized room, door half open, ventilation rate $4.1 \mathrm{~m}^{3} / \mathrm{min}$, refrigerant with $\mathrm{MW}=94 \mathrm{~kg} / \mathrm{kmole}$ leaked at $23.43 \mathrm{~kg} / \mathrm{min}(0.26-38.4 \mathrm{~s}$ duration), $1.219 \mathrm{~m}$ above floor.

Leak rate was chosen to cover a wide range of scenarios including slow, low-momentum leaks and fast, catastrophic leaks. With the unit fan off, the behavior of the leaked refrigerant is highly dependent upon the leak rate. For low rates, the momentum of the refrigerant cannot overcome gravity, resulting in a cascade (or waterfall) of refrigerant into the room which then pools on the floor with very little mixing with room air. For higher rates, the leaked refrigerant enters and penetrates the room as a plume, entraining air and becoming well-mixed along the way. Accordingly, results from the sensitivity study (Figure 11) are variable with high sensitivity and inconsistent functionality to leak rate. Five values of leak rate and a higher-order functionality were chosen for defining the DoE, but this is probably still under-sampled at the lower end of the total charge parameter range. 


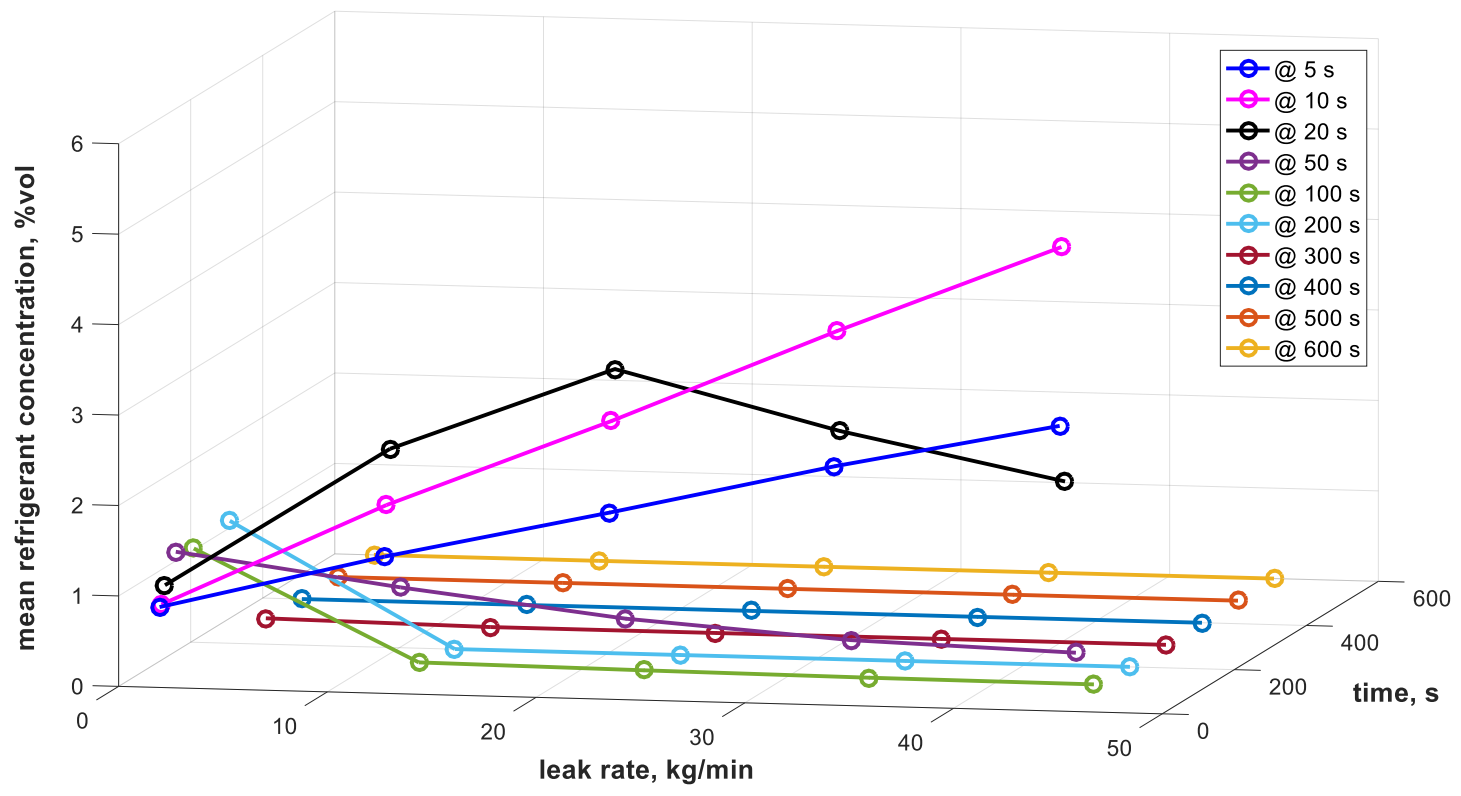

Figure 11. Impact of leak rate on mean refrigerant concentration within the room while other parameters are held constant: unit fan off, medium-sized room, door half open, ventilation rate $4.1 \mathrm{~m}^{3} / \mathrm{min}, 7.55 \mathrm{~kg}$ of refrigerant with $M W=94 \mathrm{~kg} / \mathrm{kmole}$ leaked (3.7-241.6 $\mathrm{s}$ duration), $1.219 \mathrm{~m}$ above floor.

The final parameter in the DoE is the refrigerant itself. While at first it would seem an overwhelming task to capture the impact of refrigerant choice in a single ROM, the behavior of the refrigerant in the CFD simulations is primarily dependent upon its molecular weight. The weight of the refrigerant plays a large role in how the refrigerant distributes and mixes within the room, especially for low-momentum leaks as discussed above. The impacts of other fluid properties are either minor or covered by appropriately selecting the range of other parameters. As described above, the maximum allowable charge for each refrigerant was accounted for when selecting the range for the total charge parameter. The operating pressure of the refrigerant in the system will impact the leak rate, but that can also be accounted for by selecting a sufficiently large range for that parameter. To test the impact of other fluid parameters including operating temperature, viscosity, and thermal conductivity, simulations were performed under identical conditions using different refrigerants but with the molecular weight of the refrigerants set equal. No significant differences were observed in those simulation results. The flammability limits of the refrigerant will impact the calculation of flammable volumes during post-processing of the CFD results, but not the raw CFD results themselves.

The sensitivity of the CFD simulations was found to decrease asymptotically with higher molecular weight refrigerants as shown in Figure 12. The impact of molecular weight was also found to vary with leak rate. For low leak rates, there is a high sensitivity to molecular weight due to gravity overcoming momentum, whereas sensitivity to molecular weight is low at higher leak rates when momentum is sufficient for the refrigerant to enter as a plume and mix well with room air. Based on the refrigerants chosen for inclusion (see Table 4) and the observed sensitivity, a range of $44-114 \mathrm{~kg} / \mathrm{kmole}$ and five sample points were used in the DoE. 


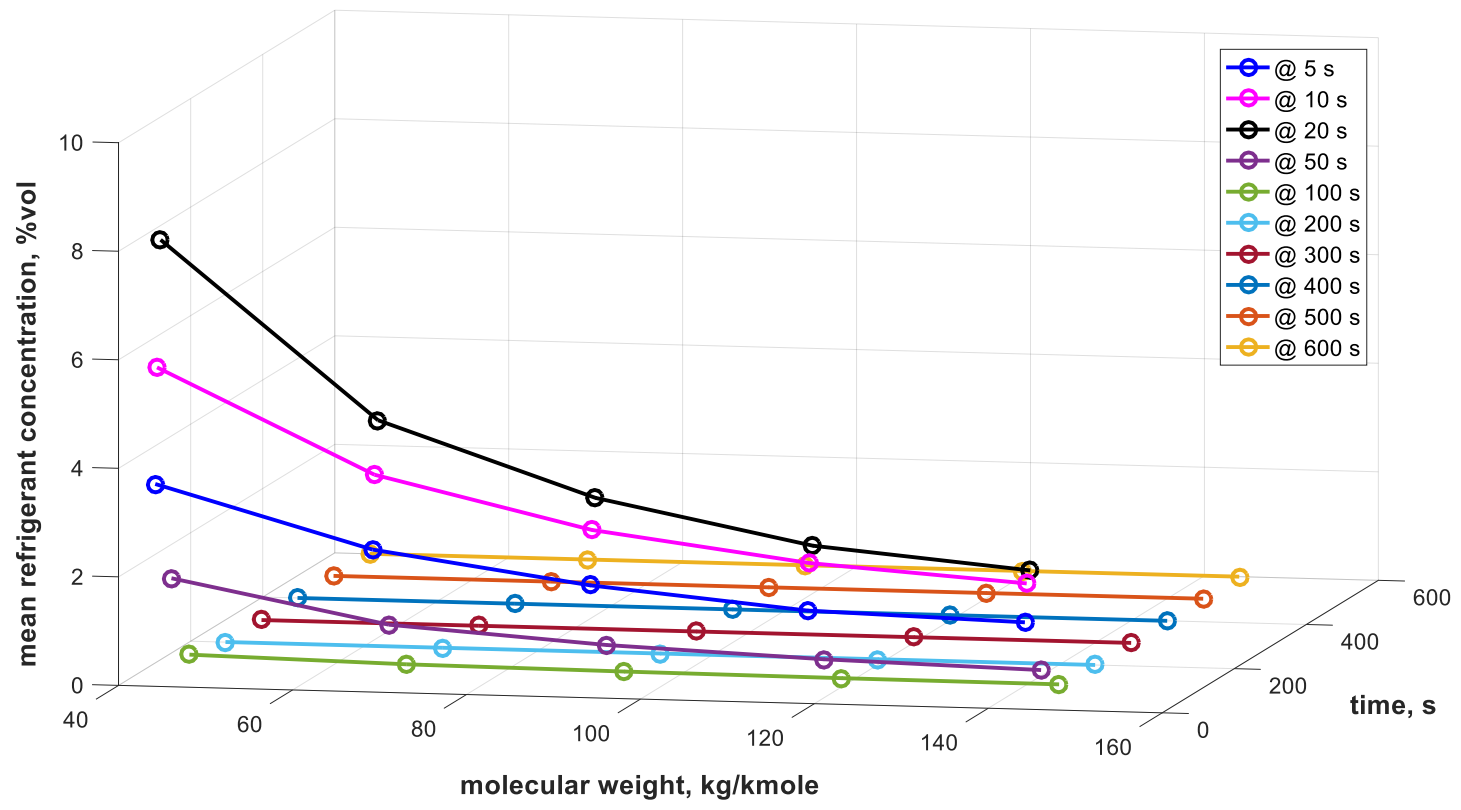

Figure 12. Impact of molecular weight on mean refrigerant concentration within the room while other parameters are held constant: unit fan off, medium-sized room, door half open, ventilation rate $4.1 \mathrm{~m}^{3} / \mathrm{min}$, $7.55 \mathrm{~kg}$ of refrigerant leaked at $23.43 \mathrm{~kg} / \mathrm{min}(19.3 \mathrm{~s}$ duration $), 1.219 \mathrm{~m}$ above the floor. 
Table 4. Molecular weight (MW), LFL, and UFL for refrigerants used to generate the ROMs

\begin{tabular}{ccccc}
\hline Refrigerant & $\begin{array}{c}\text { MW } \\
(\mathbf{k g} / \mathbf{k m o l e})\end{array}$ & $\begin{array}{c}\text { LFL } \\
(\boldsymbol{\%} \mathbf{~ v / v})\end{array}$ & $\begin{array}{c}\text { UFL } \\
(\mathbf{\%} \mathbf{~ v} \mathbf{v})\end{array}$ & $\begin{array}{c}\text { Source } \\
\text { MSDS } \mathbf{1}, \text { year }\end{array}$ \\
\hline R-290 & 44 & 1.8 & 8.4 & Airgas, 2017 \\
\hline R-600a & 58.1 & 1.8 & 8.4 & $\begin{array}{c}\text { National } \\
\text { Refrigerants, 2015 }\end{array}$ \\
\hline R-600 & 58.1 & 1.9 & 8.5 & Matheson, 2018 \\
\hline R-1270 & 42.1 & 2.5 & 10.1 & $\begin{array}{c}\text { National } \\
\text { Refrigerants, 2013 }\end{array}$ \\
\hline R-1150 & 28.1 & 2.7 & 36 & $\begin{array}{c}\text { National } \\
\text { Refrigerants, 2015 }\end{array}$ \\
\hline R-170 & 30 & 3 & 12.5 & $\begin{array}{c}\text { National } \\
\text { Refrigerants, 2015 }\end{array}$ \\
\hline E-170 & 46 & 3.3 & 26.2 & Airgas, 2015 \\
\hline R-152a & 66 & 3.7 & 18 & Airgas, 2016 \\
\hline R-160 & 64.5 & 3.8 & 15.4 & Praxair, 2016 \\
\hline R-50 & 16 & 5 & 15 & Praxair, 2009 \\
\hline R-1234yf & 114 & 6.2 & 12.3 & Honeywell, 2015 \\
\hline R-143a & 84 & 7.4 & 18.8 & Airgas, 2015 \\
\hline R-40 & 50.5 & 8.1 & 17.4 & Airgas, 2015 \\
\hline R-30 & 84.9 & 12 & 19 & Science Lab, 2013 \\
\hline R-32 & 52 & 13 & 33 & Airgas, 2015 \\
\hline
\end{tabular}

${ }^{1}$ Material Safety Data Sheet

\section{REDUCED ORDER MODEL CORRELATIONS}

After the CFD simulations were completed, the outputs of interest were extracted. These results were then imported into Tasmanian to develop the ROM. The development of the correlations is described in the following sections.

\subsection{CALCULATION OF DESIRED OUTPUTS FROM RAW CFD RESULTS}

Raw results from each of the CFD simulations include an output file at every second of the simulation (601 total files from 0-600 s of simulated time) which contains the location, volume, composition, and thermophysical conditions (temperature, pressure, fluid velocity, etc.) of every computational cell in the model domain. Each case generated approximately 3 to $15 \mathrm{~GB}$ of data depending upon room size and test conditions. These data can be used to visualize the dispersion of refrigerant using tools such as EnSight [19] or ParaView [20]. For generation of the ROM, MATLAB [2] scripts were used to extract the spatial and temporal concentration data for each cell from the raw CFD results and to calculate the 396 outputs of interest for all cases including:

- Refrigerant concentration: maximum and spatiotemporal mean across entire room plus min, mean, and max temporal profiles at 5, 10, 20, 50, 100, 200, 300, 400, 500 and 600 seconds

- Flammable volume fraction (FVF, 0-1) and accumulated fuel volume fraction (AFV, 0-1) 
- FVF is the volume in the room that has a concentration between the LFL and UFL at any time divided by the total volume of the room. FVF is an important input to probability risk assessments (PRA) as an indication of the likelihood of an ignition event.

- $\mathrm{AFV}$ is the volume in the room that has a concentration greater than the LFL at any time divided by the total volume of the room. AFV is an important input to PRAs as an indication of the severity of an ignition event

- FVF and AFV were calculated for each combination of LFL and UFL in Table 4.

○ The following stats were calculated

- Temporal maximum and mean of FVF and AFV

- Total time duration for some FVF and AFV

- FVF and AFV temporal profile at 5, 10, 20, 50, 100, 200, 300, 400, 500 and 600 seconds

The MATLAB script then compiles an input file for Tasmanian which contains the seven input parameters and the outputs of interest for each case.

\subsection{CONSTRUCTING SURROGATE MODEL USING TASMANIAN}

Tasmanian [1] is an ORNL-developed, high-performance library for surrogate modeling and Bayesian inference with focus on applications of uncertainty quantification and model validation verification and calibration. In this project, we used the sparse grids approximation techniques implemented in Tasmanian, specifically the hierarchical methods that use linear piece-wise polynomial basis [15]. Given a complex computational model, i.e., the CFD model, and given a select set of input parameters with corresponding ranges, e.g., molecular density or leak height, Tasmanian is used to generate a grid that consists of combinations of values for the inputs. CFD model simulations are performed with the corresponding inputs and the result (output) of the simulation is then given back to Tasmanian. The output data are analyzed and compiled into a Tasmanian grid file, and the compiled file can be used to infer model outputs for any arbitrary values of the input parameters, so long as they fall within the initially specified ranges. The computational cost of this approximate (surrogate) model is negligible compared to the full CFD, thus thousands of samples can be computed, and rigorous statistical analysis can be performed. The Tasmanian grid file requires an installation of the Tasmanian library, but it can be used from within Python (e.g., anaconda) or MATLAB (or GNU/Octave) environments.

In this project, we used expert knowledge to introduce a bias in the sparse grids construction, so that the final surrogate will deliver more accurate results with the same number of full CFD model simulations. First, non-linear transformation was used for the room height, ventilation rate, and leak height parameters; as a result, more samples were collected for small room sizes and ventilation rates, and the leak heights for all grid points were aligned with the three baseline cases (leading to better accuracy for those cases). Then, CFD simulations were performed with inputs from a coarse sparse grid and a subset of a much denser grid (performing all CFD simulations on the denser grid is prohibitively expensive and the subset was chosen with expert opinion). The CFD simulation data were then projected on the entire denser grid using the least-squares method described in [21]. Effectively, the projection removed any missing or redundant points in the grid and minimized the size of the Tasmanian grid file while preserving the accuracy of the surrogate model. 


\subsection{FINAL MODELS}

This section describes the development of the two ROMs (aka, surrogate models) with the unit circulation fan off and on based on the post-processed CFD simulation results. An evaluation of the predictive accuracy of the "fan off" ROM is also included.

\subsubsection{ROM 1: AC unit fan off version \& sample results}

Following a traditional sparse grids approach, an initial sampling of 108 cases was selected focused on the center of the parameter space and branching out along each parameter axis and key diagonals. However, based on the results of the sensitivity study presented above, it became clear that additional cases were needed along the edges and corners of the parameter space due to the high sensitivities noted in these areas. The final DoE consisted of results from 586 CFD training cases with sample points for the 7 input parameters as given in Table 3. Values for the 7 input parameters and 396 output values for each of the 586 cases were used in Tasmanian to develop the final ROM.

In constructing the fit, Tasmanian minimizes the residual error at the sample points. The true goodness of fit is therefore determined by how well the fit predicts the response at points that lie between the sample points. To provide an initial assessment of the ROM accuracy, 11 additional test cases, shown in Table 5, were run with both the CFD model and the ROM. The input values for these validation cases were specifically chosen to align with parameter sweeps in the training data to evaluate the accuracy of the ROM at locations between sample points where high sensitivity and higher-order functionality were observed and largest errors might be expected.

Table 5. Input parameters for the validation cases. The highlighted cells are values that were not used in training the ROM.

\begin{tabular}{cccccccc}
\hline $\begin{array}{c}\text { Case } \\
\text { number }\end{array}$ & $\begin{array}{c}\text { Floorplan } \\
\text { area } \\
\mathbf{m}^{\mathbf{2}}\end{array}$ & $\begin{array}{c}\text { Leak } \\
\text { height } \\
\mathbf{m}\end{array}$ & $\begin{array}{c}\text { Open door } \\
\mathbf{a r e a} \\
\mathbf{m}^{\mathbf{2}}\end{array}$ & $\begin{array}{c}\text { Ventilation } \\
\text { rate } \\
\mathbf{3} \mathbf{3} \mathbf{m i n}\end{array}$ & $\begin{array}{c}\text { Total } \\
\text { charge } \\
\mathbf{~ k g}\end{array}$ & $\begin{array}{c}\text { Leak rate } \\
\mathbf{k g} / \mathbf{m i n}\end{array}$ & $\begin{array}{c}\text { MW } \\
\mathbf{k g} / \mathbf{k m o l e}\end{array}$ \\
\hline $\mathbf{1}$ & 5 & 1.822 & 0.0116 & 2.8 & 15 & 1.875 & 44 \\
\hline $\mathbf{2}$ & 5 & 1.822 & 0.0116 & 5.7 & 15 & 1.875 & 44 \\
\hline $\mathbf{3}$ & 5 & 1.822 & 0.0116 & 9.9 & 15 & 1.875 & 44 \\
\hline $\mathbf{4}$ & 10 & 1.219 & 0.988 & 4.1 & 7.55 & 23.43 & 57 \\
\hline $\mathbf{5}$ & 10 & 1.219 & 0.988 & 4.1 & 7.55 & 23.43 & 84 \\
\hline $\mathbf{6}$ & 10 & 1.219 & 0.988 & 4.1 & 1 & 23.43 & 94 \\
\hline $\mathbf{7}$ & 10 & 1.219 & 0.988 & 4.1 & 5.5 & 23.43 & 94 \\
\hline $\mathbf{8}$ & 10 & 1.219 & 0.988 & 4.1 & 7.55 & 4 & 94 \\
\hline $\mathbf{9}$ & 10 & 1.219 & 0.988 & 4.1 & 7.55 & 6 & 94 \\
\hline $\mathbf{1 0}$ & 10 & 1.219 & 0.988 & 4.1 & 7.55 & 8 & 94 \\
\hline $\mathbf{1 1}$ & 10 & 1.219 & 0.988 & 4.1 & 7.55 & 28 & 94 \\
\hline
\end{tabular}

The ROM was found to do a good job predicting the mean refrigerant concentration for the 11 test cases. As was shown in Figure 9, mean concentration was found to have high sensitivity and higher-order functionality with changes in ventilation rate when the room door is closed. Figure 13 provides a qualitative measure of goodness of fit for five of the ROM outputs (mean concentration at 20, 100, 200, 300 , and $400 \mathrm{~s}$ ) during a parametric sweep of ventilation rate at the same conditions as in Figure 9 . In addition to CFD results for the 4 training cases shown in Figure 9, Figure 13 includes CFD and ROM 
results for test cases 1-3 which were chosen to coincide with areas of high sensitivity and higher-order functionality in the model response. As shown, the ROM agrees well with the CFD results for these cases capturing both the functionality and sensitivity of the output trends between sample points as well as the absolute values of mean concentration with an average error of $0.67 \%$ and a maximum error of $15 \%$ occurring for the 20 -s output value with a rate of $9.9 \mathrm{~m}^{3} / \mathrm{min}(350 \mathrm{cfm})$. Figure 14 shows the predicted history of mean concentration over time for the 4 training and 3 test cases which can be reconstructed from 10 of the model output parameters (mean concentration at 5, 10, 20, 50, 100, 200, 300, 400, 500 and $600 \mathrm{~s}$ ). Again, qualitatively, the ROM does a good job of capturing the observed trends although quantitatively, the error is higher than desired at some of the points (especially late in the simulation) with a maximum error of $33 \%$ for the 600 -s output variable at a ventilation rate of $9.9 \mathrm{~m}^{3} / \mathrm{min}$.

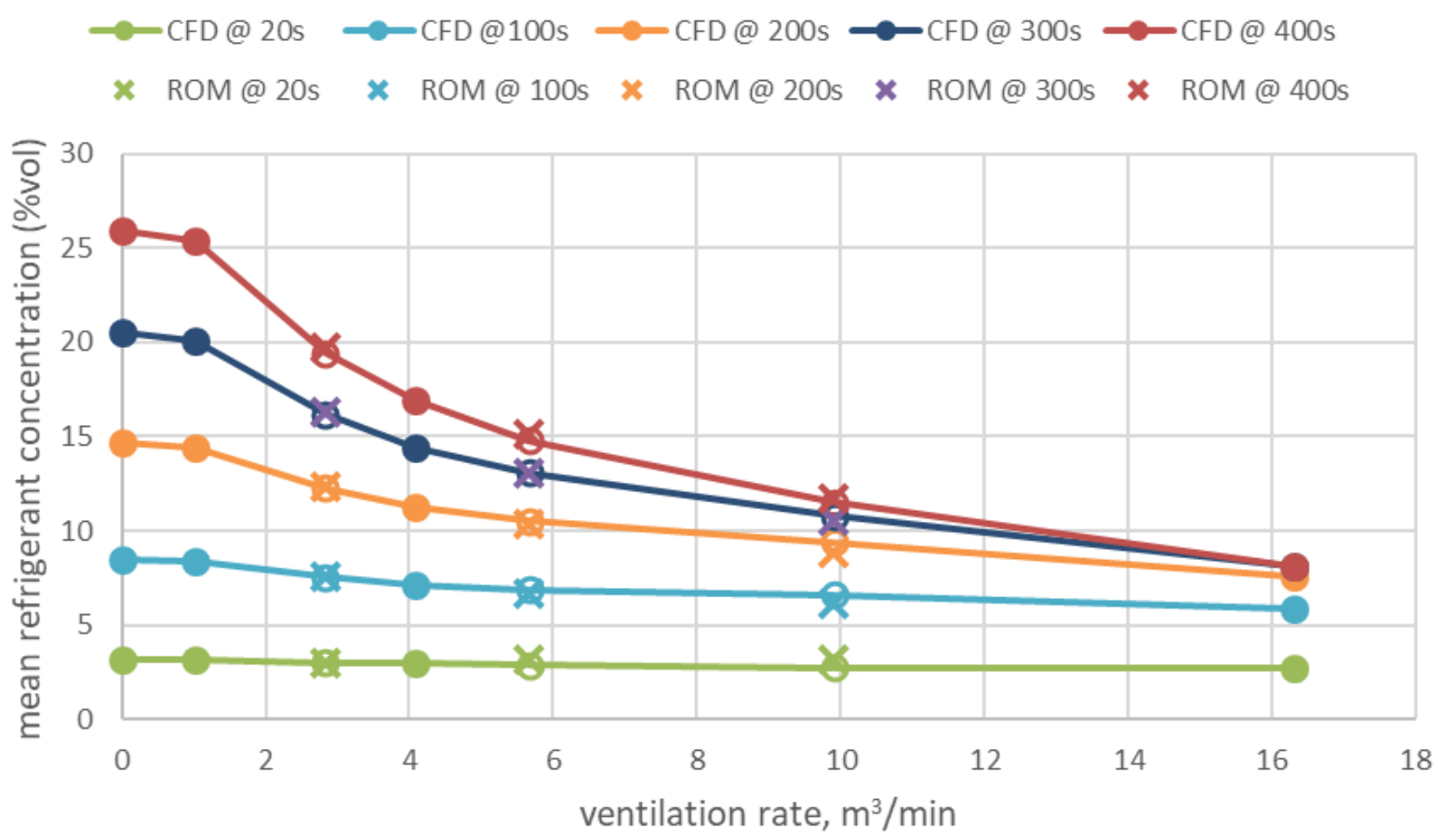

Figure 13. Comparison of predicted mean refrigerant concentration with the CFD model (open circles) and ROM (" $x$ "s) at three test points selected to fall within high sensitivity response regions with limited sampling in CFD training cases (solid dots). Unit fan off, small-sized room, door closed, $15 \mathrm{~kg}$ of refrigerant with $M W=44 \mathrm{~kg} / \mathrm{kmole}$ leaked at $1.875 \mathrm{~kg} / \mathrm{min}$ (480 $\mathrm{s}$ duration), $1.822 \mathrm{~m}$ above floor. 


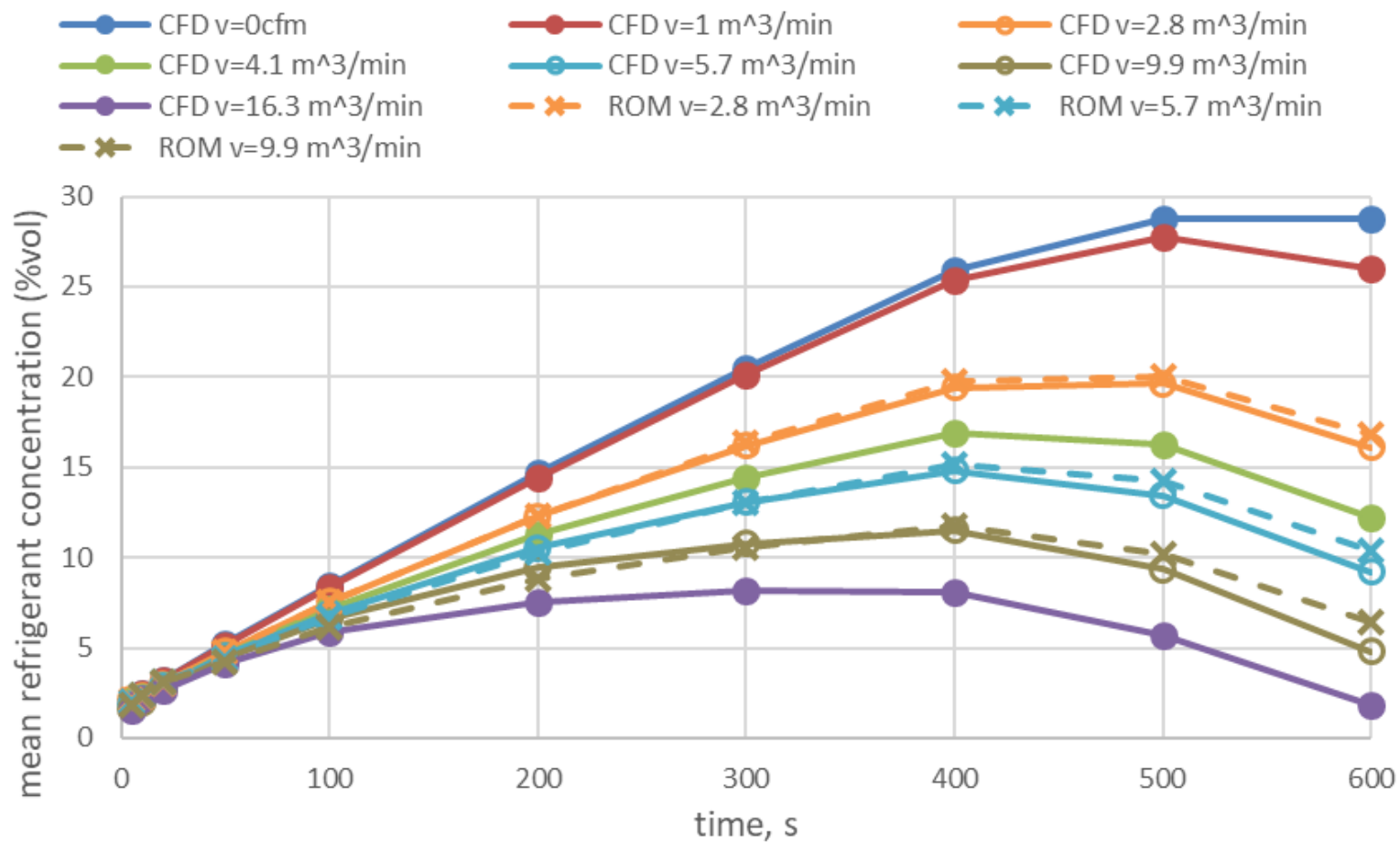

Figure 14. History of mean refrigerant concentration for different ventilation rates with comparison of CFD (open circle) and ROM ("X"s) predictions at three test points. Unit fan off, small-sized room, door closed, 15 $\mathrm{kg}$ of refrigerant with $\mathrm{MW}=44 \mathrm{~kg} / \mathrm{kmole}$ leaked at $1.875 \mathrm{~kg} / \mathrm{min}$ (480 s duration), $1.822 \mathrm{~m}$ above floor.

The current ROM does less well at predicting many of the other target output parameters. For the eleven test cases, the maximum absolute error in the maximum FVF was $1.32 \%$ and the maximum absolute error in the duration of FVF was 205.64 seconds. The root mean square error (RMSE) of those two outputs for the eleven cases were $0.5 \%$ and 77.74 seconds, respectively. Figure 15 shows the RMSE for the prediction of the maximum refrigerant concentration in the space $(\% \mathrm{v} / \mathrm{v})$ for all test cases presented in Table 5, and for each of the 10 simulation time steps that the ROM outputs. Figure 15 shows that the RMSE for the maximum refrigerant concentration is within $20 \%$ except for the cases between about 50 s and 200s. Furthermore, the maximum absolute error in the maximum refrigerant concentration was $71 \%$ for case number 8 . 


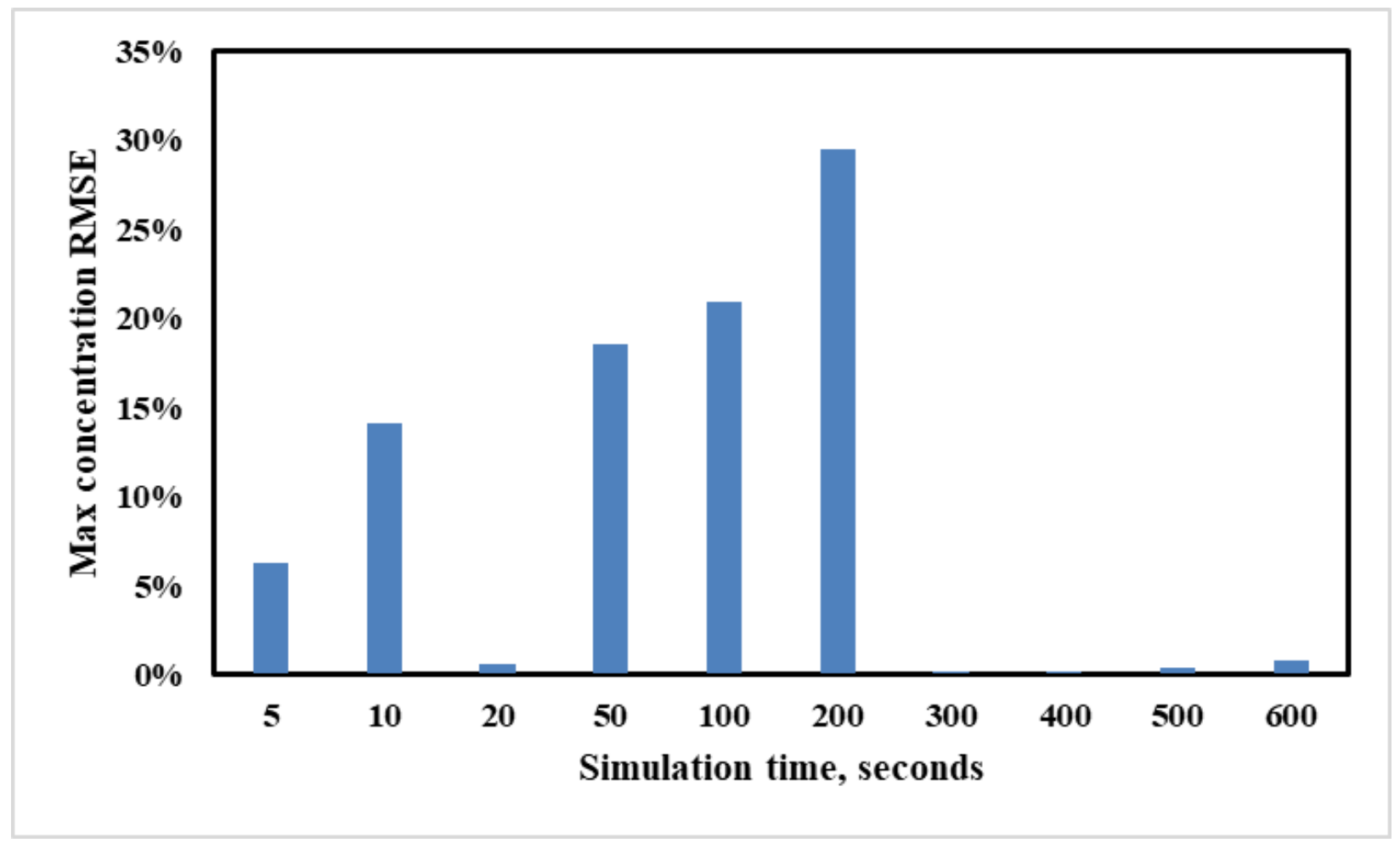

Figure 15. Root mean square error (RMSE) of maximum refrigerant concentration in the room space at different simulation times

These errors are largely due to low grid sampling in areas where these parameters exhibit high sensitivity and higher-order functionality. The initial sensitivity studies for the input parameter used to determine the sampling levels and fit functionality only considered mean refrigerant concentration. Later, additional parameters were selected for inclusion in the ROM outputs which may exhibit different responses requiring additional grid refinement.

As examples, Figures 16-18 show the predicted outputs during a parametric sweep of ventilation rate for five of the ROM output parameters: the temporally averaged FVF in the room, the duration with some FVF in the room, and the spatially averaged FVF at 200, 300 and 400s (all calculated based on the flammability range of R-32). Most of these output parameters show a high-order functionality with highest sensitivity occurring in the large sampling gap between 4.1 and $15.2 \mathrm{~m}^{3} / \mathrm{min}(144$ and $538 \mathrm{cfm}$ ). As a result, the ROM does a poor job predicting the outputs in those areas. The skewed distribution of sampling points for the ventilation rate input parameter was chosen to capture the high sensitivity of mean refrigerant concentration at low ventilation rates (see Figure 9), and as shown in Figure 13, the ROM performs well for this parameter. Similarly, the output variable for spatially averaged mean FVF at $200 \mathrm{~s}$ shows greatest sensitivity at lower ventilation rates (Figure 18), and as a result the ROM also predicts this parameter well. While this discussion has focused on differences in the response of the output parameters to changes in ventilation rate, similar trends are observed for the other input parameters.

To achieve better agreement for all output parameters, further refinement of the sparse grids sampling strategy is needed. CFD results from the additional training cases can then be included to develop a refined ROM. 


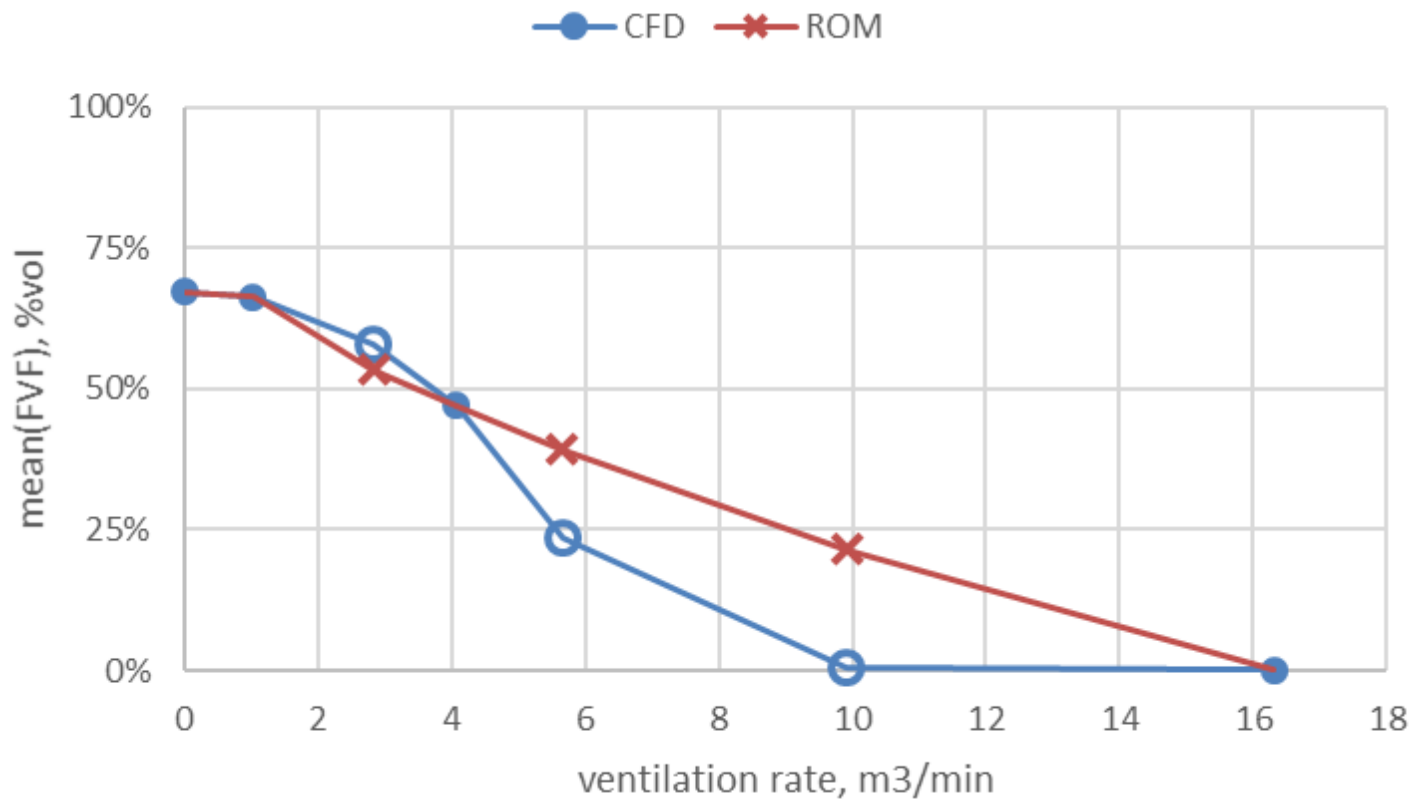

Figure 16. Comparison of predicted temporal mean of FVF using CFD model (open circles) and ROM (" $\times$ "s) at three test points falling between training samples (solid dots). Unit fan off, small-sized room, door closed, $15 \mathrm{~kg}$ of refrigerant with $\mathrm{MW}=44 \mathrm{~kg} / \mathrm{kmole}$ leaked at $1.875 \mathrm{~kg} / \mathrm{min}$ (480 s duration), $1.822 \mathrm{~m}$ above floor.

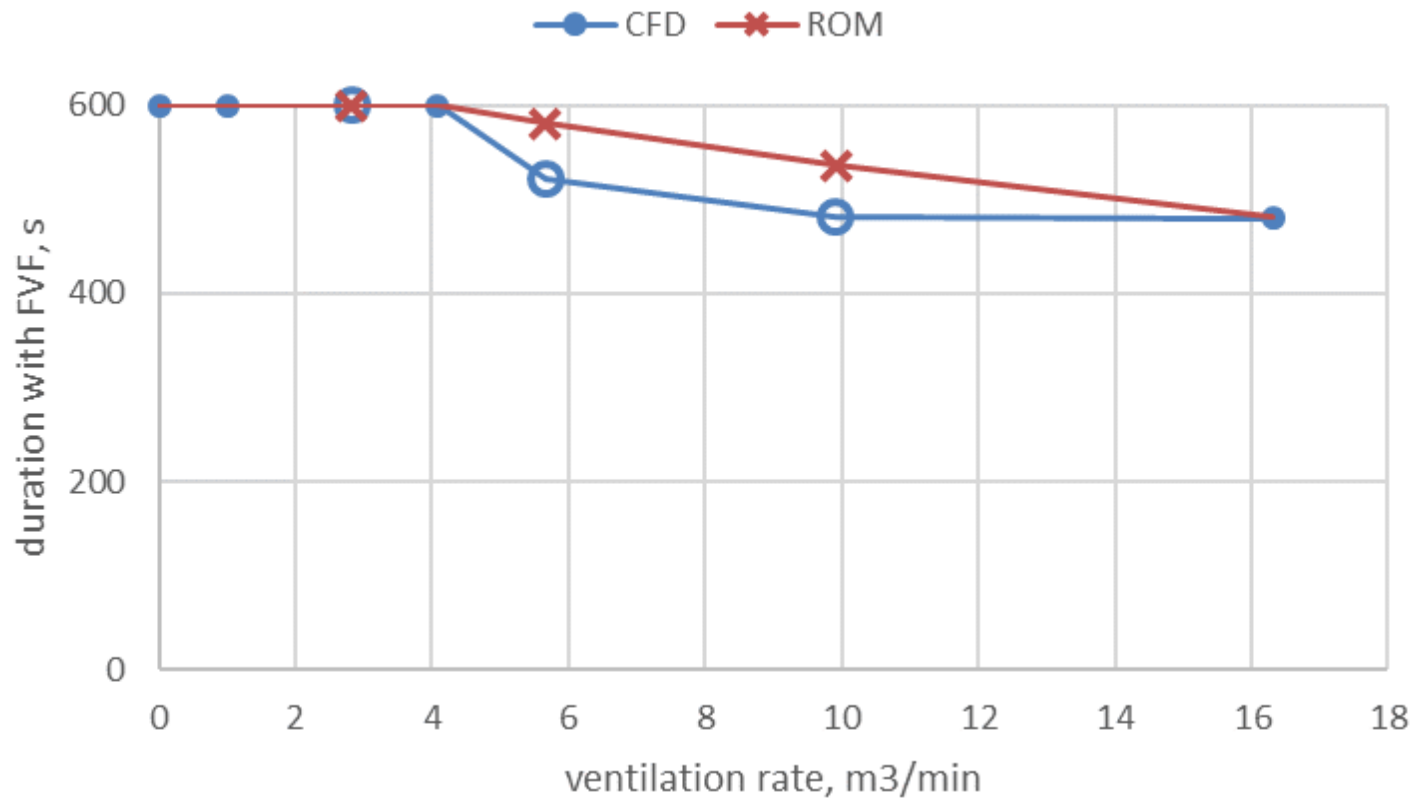

Figure 17. Comparison of predicted duration with a FVF in the room using CFD model (open circles) and ROM (" $x$ "s) at three test points falling between training samples (solid dots). Unit fan off, small-sized room, door closed, $15 \mathrm{~kg}$ of refrigerant with $M W=44 \mathrm{~kg} / \mathrm{kmole}$ leaked at $1.875 \mathrm{~kg} / \mathrm{min}$ (480 s duration), $1.822 \mathrm{~m}$ above floor. 


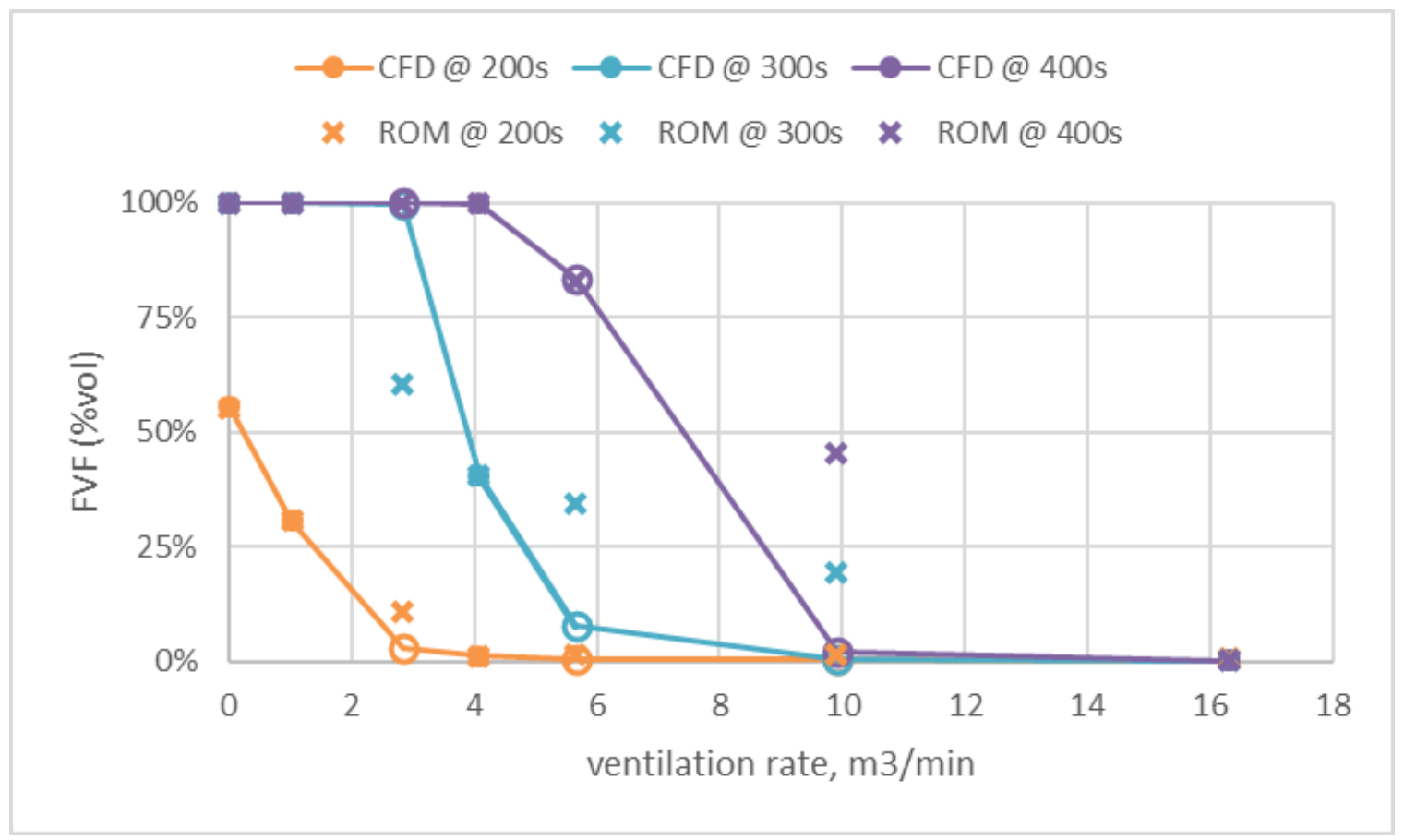

Figure 18. Comparison of predicted FVF at selected times using CFD model (open circles) and ROM (" $x$ "s) at three test points falling between training samples (solid dots). Unit fan off, small-sized room, door closed, 15 $\mathrm{kg}$ of refrigerant with $\mathrm{MW}=44 \mathrm{~kg} / \mathrm{kmole}$ leaked at $1.875 \mathrm{~kg} / \mathrm{min}(480 \mathrm{~s}$ duration), $1.822 \mathrm{~m}$ above floor.

\subsubsection{ROM 2: AC unit fan on version - development status}

CFD simulations using CONVERGE v2.4 are underway to support development of the "fan on" ROM (system circulation fan is on). This scenario requires a more detailed model to include recirculation of room air through the unit. With the help of developers at Convergent Science, Inc. (CSI) a user-defined function (UDF) was developed for use with the existing room model to simulate intake of air/refrigerant mixture from the room into the unit's return duct and subsequent reintroduction of that mixture (with the same composition) back to the room through the unit's supply duct. Using the Tasmanian sparse grids approach, an initial set of 576 cases was selected for simulation to train the ROM. As of the end of November about $68 \%$ of the "training" simulations are complete. Most of the remaining cases are for the largest room volume and are taking about $20 \mathrm{~h}$ each to complete. Completion of the "fan on" ROM is expected in 2019 and will be reported in a separate publication. 


\section{CONCLUSIONS}

This report provides a detailed description of the development of a reduced order model (ROM) that could be used for estimation of safe charge limits based on a computational fluid dynamics (CFD) parametric study. The ROM was developed to simulate leak events from a single side-wall duct penetration into a room and provide estimates of refrigerant concentration together with flammable volume fraction (FVF) and other outputs vs. time. It is based on the parameters given in Table 3 and assumes that the AC unit air circulation blower is off. A total of 586 CFD "training" cases were run and used as the basis for development and training of the ROM. The regression analysis used to develop the ROM was performed in Tasmanian (Toolkit for $\underline{\text { Adaptive }} \underline{\text { Stochastic }}$ Modeling $\underline{\text { And }}$ Non-Intrusive Approximation) $)^{3}$. This is a tool developed at ORNL for high dimensional integration, interpolation and parameter calibration. Comparison of the ROM vs. several CFD test cases (at points not used in the training set) showed maximum absolute and root mean square errors (RMSE) for FVF of $1.32 \%$ and $0.5 \%$, respectively. Other output metrics were predicted less accurately but could be improved with additional sampling to further refine the ROM. It should be noted that Tasmanian does not produce a closed-form equation for the ROM. Two appendices to this report (APPENDIX A and APPENDIX B) describe in detail how to install Tasmanian and run the ROM.

A second ROM is in development as well. This ROM will be similar to the ROM described in this report except for the assumption that the AC blower is in operation. A set of 576 "training" CFD simulations are in process. Development of the second ROM will be described in a subsequent publication.

\footnotetext{
${ }^{3}$ https://tasmanian.ornl.gov/
} 


\section{REFERENCES}

[1] Stoyanov, M., 2018, User Manual: Toolkit for Adaptive Stochastic Modeling and Non-Intrusive Approximation, version 6.0, ORNL/TM-2015/596.

[2] The MathWorks, Inc., 2018, MATLAB, Natick, MA, USA.

[3] UNEP, 2016, "The Kigali Amendment to the Montreal Protocol: HFC Phase-down," United Nations Environment Program OzonAction Fact Sheet, http://multimedia.3m.com/mws/media/1365924O/unepfact-sheet-kigali-amendment-to-mp.pdf.

[4] ASHRAE, 2016, ASHRAE 34-2016 - Designation and Safety Classification of Refrigerants, Addendum g, American Society of Heating, Refrigerating and Air-Conditioning Engineers.

[5] ISO, 2014, ISO 817:2014 Refrigerants - Designation and Safety Classification, International Organization for Standardization.

[6] IEC, 2018, IEC 60335-2-40:2018 Household and Similar Electrical Appliances - Safety - Part 2-40: Particular Requirements for Electrical Heat Pumps, Air-conditioners and Dehumidifiers, International Electrotechnical Commission.

[7] UL, 2017, UL 60335-2-40:2017 Household and Similar Electrical Appliances - Safety - Part 2-40: Particular Requirements for Electrical Heat Pumps, Air-conditioners and Dehumidifiers, Underwriters Laboratories.

[8] ISO, 2014, ISO 5149 Refrigerating Systems and Heat Pumps: Safety and Environmental Requirements, International Organization for Standardization.

[9] ASHRAE, 2016, ASHRAE 15-2016 - Safety Standard for Refrigeration Systems, American Society of Heating, Refrigerating and Air-Conditioning Engineers.

[10] UL, 2010, UL 471 - Standard for Commercial Refrigerators and Freezers, Underwriters Laboratories.

[11] UL, 2017, UL 60335-2-24:2017 Household and Similar Electrical Appliances - Safety - Part 2-24: Particular Requirements for Refrigerating Appliances, Ice-cream Appliances and Ice-makers, Underwriters Laboratories.

[12] UL, 2017, UL 60335-2-89:2017 Household and Similar Electrical Appliances - Safety - Part 2-89: Particular Requirements for Commercial Refrigerating Appliances with an Incorporated or Remote Refrigerant Unit or Compressor, Underwriters Laboratories.

[13] UL, 2009, UL 563 - Standard for Ice Makers, Underwriters Laboratories.

[14] Baxter, V. D., Abdelaziz, O., Abu-Heiba, A., Edwards, K. D., Elatar, A. F., FINNEY, C. E. A., Patel, V. K., and Zhang, M., 2018, "Milestone Report BTO 3.2.2.25 - Methodology for Estimating Safe Charge Limits of Flammable Refrigerants in Hvac\&R Applications - Part 1," No. ORNL/TM-2018/804 United States 10.2172/1460212 ORNL English, ; Oak Ridge National Lab. (ORNL), Oak Ridge, TN (United States). 
[15] Stoyanov, M., 2018, "Adaptive Sparse Grid Construction in a Context of Local Anisotropy and Multiple Hierarchical Parents," Proc. Sparse Grids and Applications, Miami, FL, Springer International Publishing, pp. 175-199.

[16] CONVERGENT SCIENCE, 2018, CONVERGE CFD Software, Madison, WI, USA.

[17] Dassault Systèmes SolidWorks Corporation, 2018, SolidWorks, Waltham, MA, USA.

[18] IEC, 2016, IEC 60335-2-40:2016 Household and Similar Electrical Appliances - Safety - Part 2-40: Particular Requirements for Electrical Heat Pumps, Air-conditioners and Dehumidifiers, International Electrotechnical Commission.

[19] Computational Engineering International, Inc. (wholly-owned subsidiary of ANSYS, Inc). 2018, ENSIGHT, Apex, NC, USA.

[20] Sandia National Laboratory, Kitware Inc, Los Alamos National Laboratory, 2018, ParaView, Clifton Park, NY.

[21] Stoyanov, M., Seleson, P., and Webster, C., 2017, "A surrogate modeling approach for crack pattern prediction in peridynamics," Proc. 19th AIAA Non-Deterministic Approaches Conference, Grapevine, TX, American Institute of Aeronautics and Astronautics. 


\section{APPENDIX A. TASMANIAN INSTALLATION}




$$
\text { A-2 }
$$




\section{APPENDIX A. TASMANIAN INSTALLATION}

This appendix will present a step by step instructions to install Tasmanian on a MS Windows machine. More information about the installation of Tasmanian can be found in the User Manual [1] that is included in the installation package.

1. Required software

a. Microsoft Visual Studio

i. If it is already installed on the machine, note down the version number.

ii. If it is not already installed, download it from https://visualstudio.microsoft.com/downloads/ and install it. The Community

b. CMake version is free and is enough for the installation of Tasmanian.

i. Download it at https://cmake.org/download/. You can choose the release to download. It is preferred to download the "Latest Release" and not the "Release Candidate" version. download the distribution that is appropriate for your platform (32 or 64 bit)

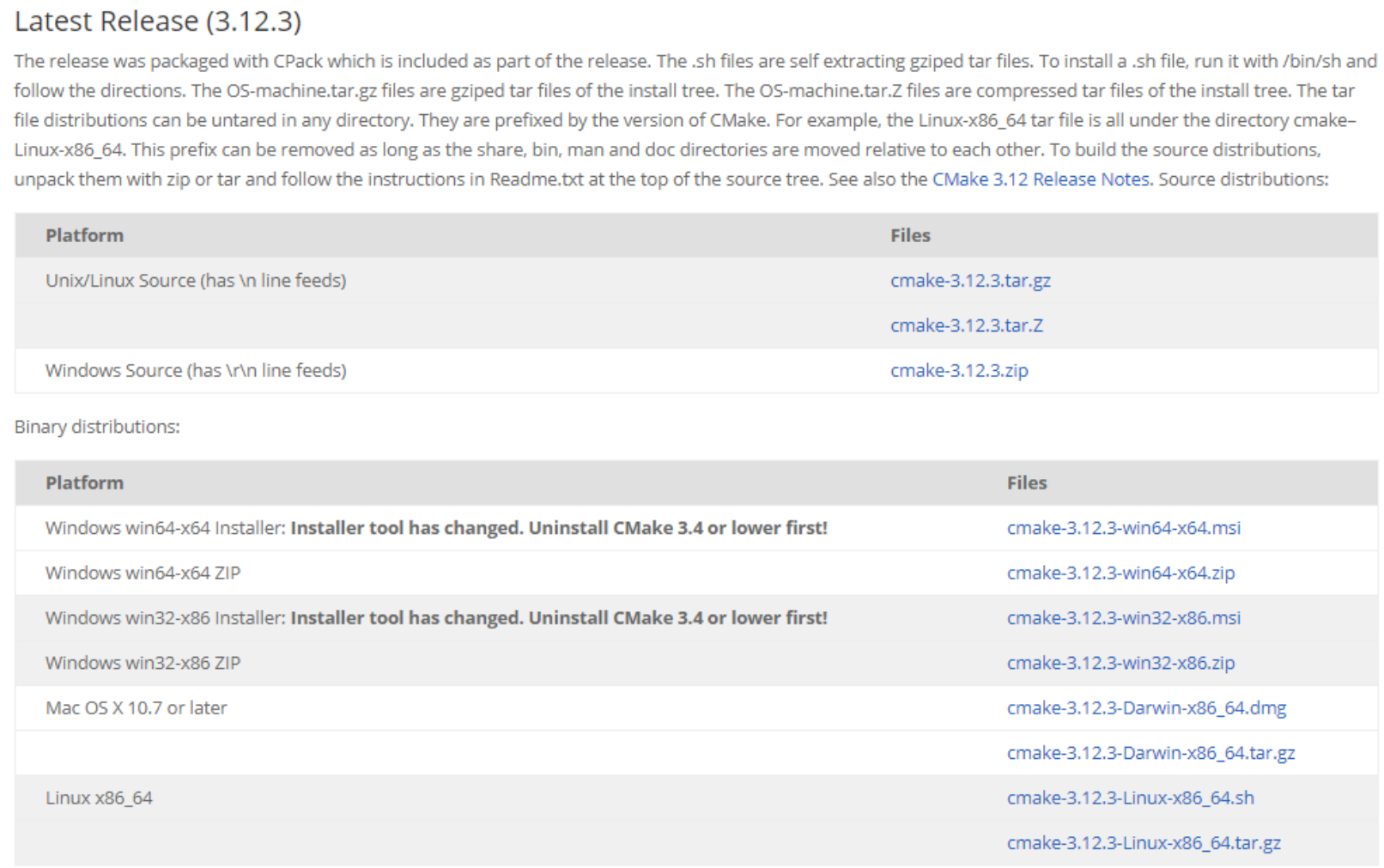

It should be noted that there are alternatives to the above software. Those specific software packages were specified only for sake of simplicity of instructions.

2. Download Tasmanian source code from https://github.com/ORNL/Tasmanian

3. Installation

a. Extract the Tasmanian source code to any directory. By default, the file will be unzipped to a directory named "Tasmanian -master". Inside this directory, there will be a folder with the same name that includes the source files. 


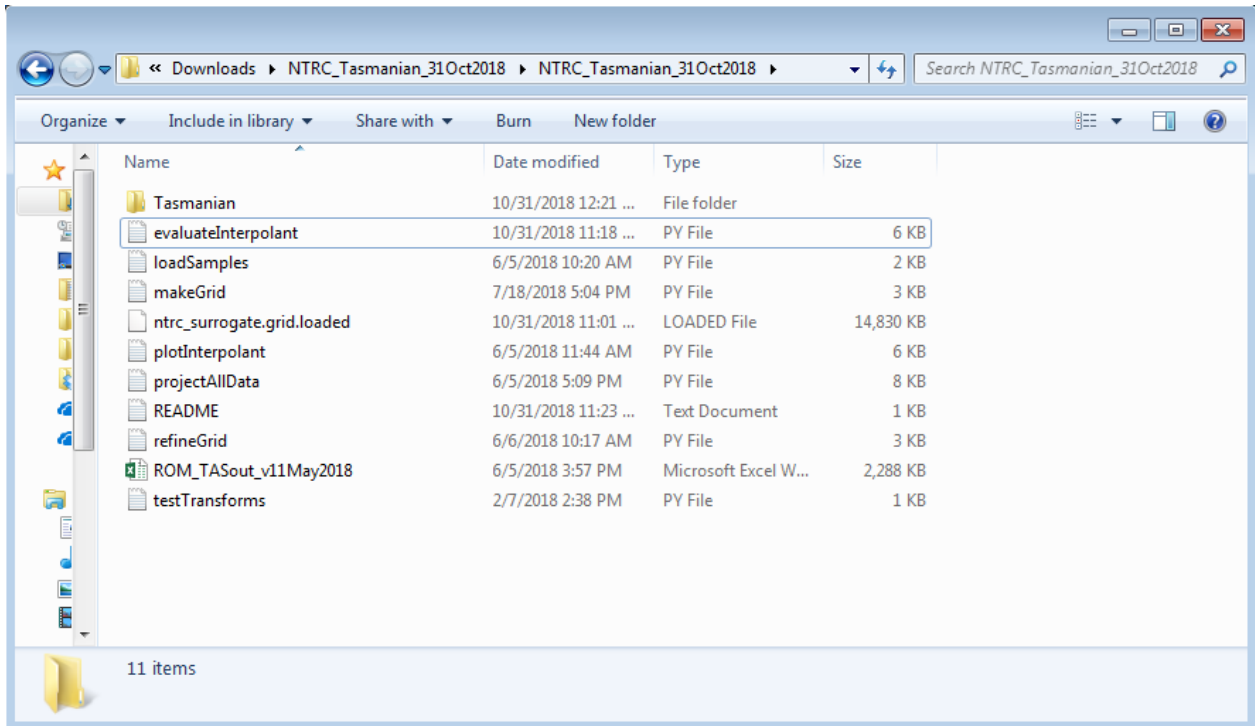

b. Create a temporary folder in a location that does not require administrator privileges to write to and give it the name "cmake_temp". This folder will no longer be needed after the installation is done.

c. Open CMake

d. Click "Browse Source..." and choose the folder that includes the Tasmanian source files. Click on "Browse Build..." and choose the "cmake temp" folder

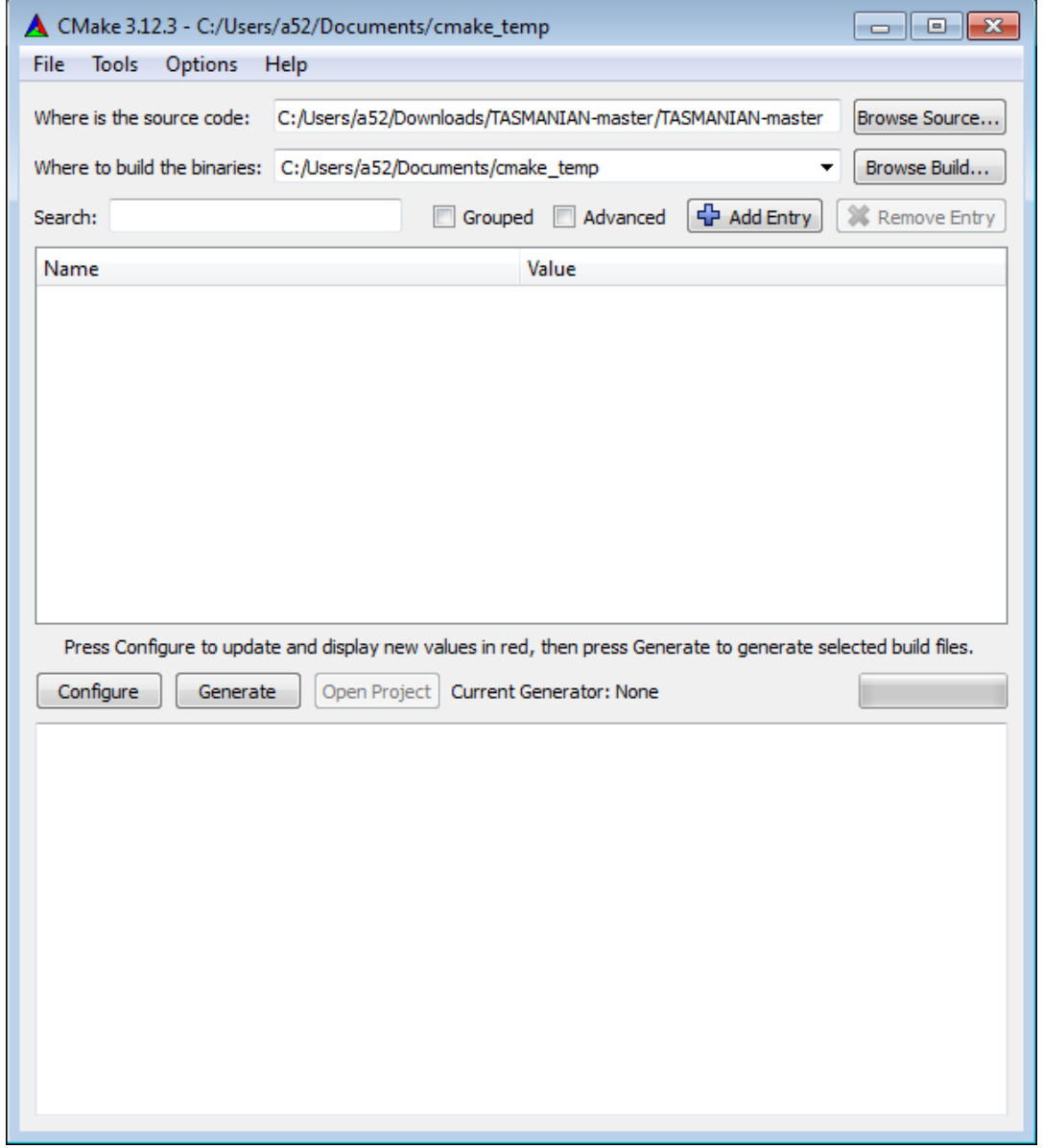


e. Click "Configure". A separate window will appear. Choose from the drop-down menu the version of Microsoft Visual Studio that is installed on the machine, then click "Finish".

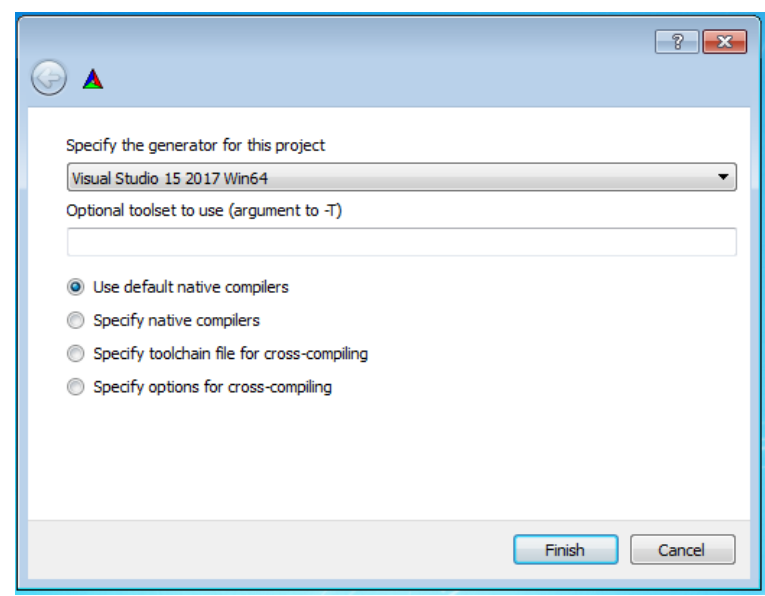

f. CMake will then complete the configuration process and will post options and results in its window

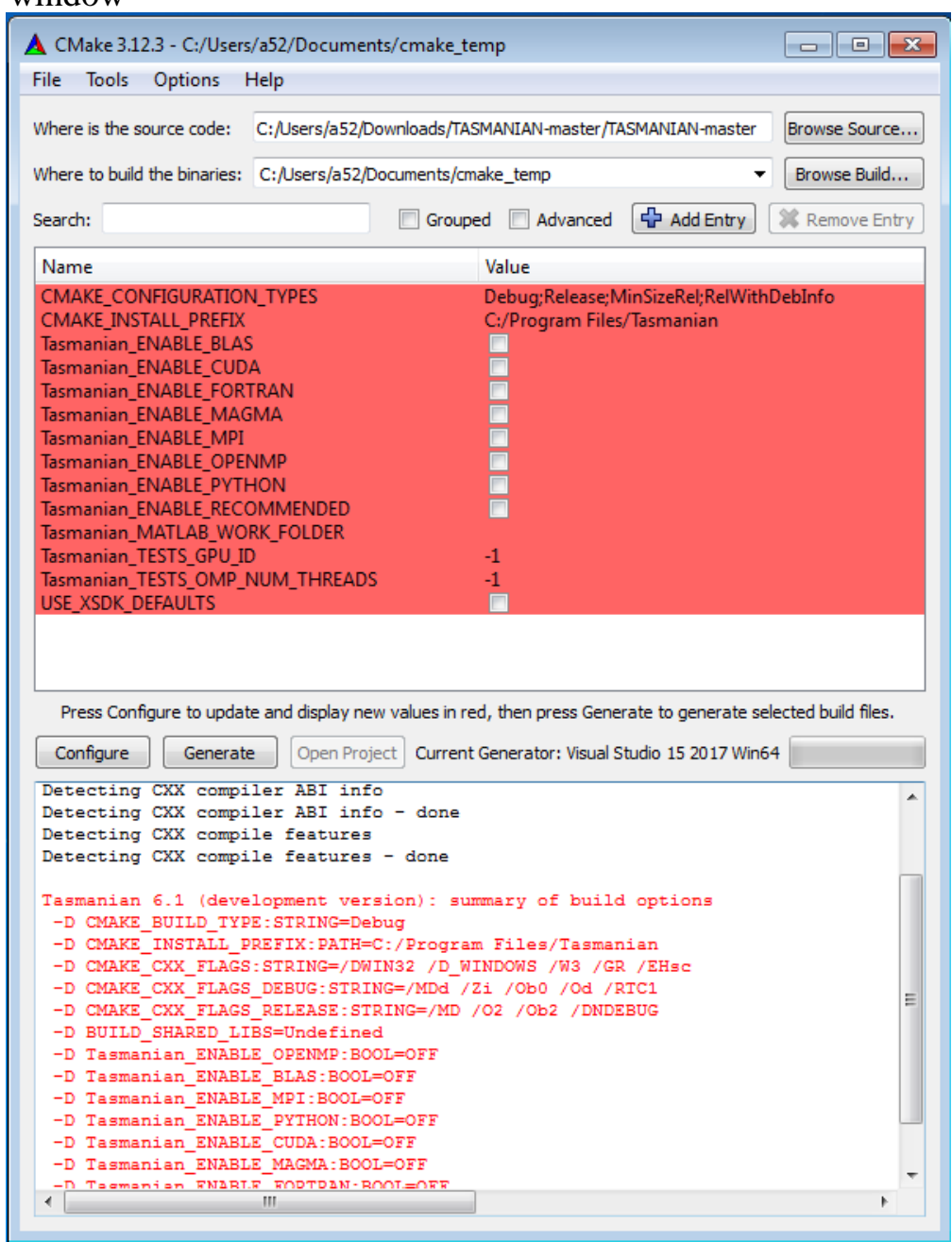

g. Check "Tasmanian_ENABLE_PYTHON" and

"Tasmanian_ENABLE_RECOMMENDED" and change the 
"CMAKE_INSTALL_PREFIX" to a directory that does not require administrator privileges to write to (as an example let's call this "C:/user/Tasmanian")

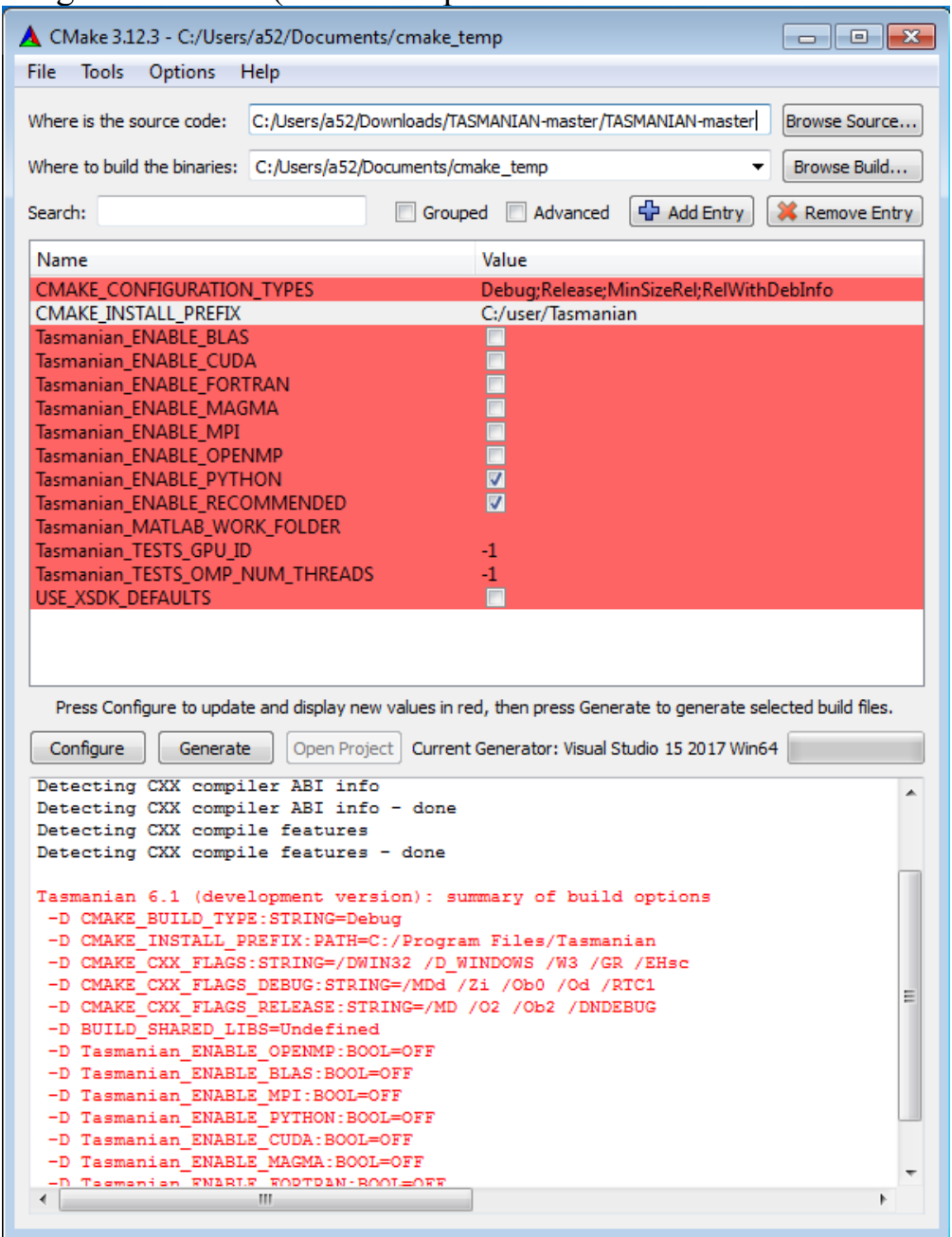

h. Click "Generate" and wait for CMake to finish. Then close CMake.

i. Open the command prompt "cmd.exe"

j. Change the directory to the "cmake_temp" directory (cd C:\....Icmake_temp)

k. Execute the following commands in order

i. Cmake -build . - config Release

ii. Ctest $-\mathrm{C}$ Release

iii. Cmake -build . - config Release -target install

1. When the execution of those commands is done, Tasmanian will be installed in the directory that was entered for the "CMAKE_INSTALL_PREFIX" in step $g$

m. Copy "evaluateInterpolant.py" and "ntrc_surrogate.grid.loaded" from the unzipped folder to the installation folder. Email abuheibaag@ornl.gov to get a copy of these files. This completes the setup of Tasmanian and it should be ready for use.

Note: Tasmanian can be used from $\mathrm{C} / \mathrm{C}++$, command line, Fortran, Python and MATLAB; but the nonlinear transformation described in this report has been implemented only in the Python script. The transformation is very problem-specific and it makes little sense to include with the library, hence the need for an extra script file (evaluateInterpolant.py). 


\section{APPENDIX B. RUNNING ROM CASES}


B-2 


\section{APPENDIX B. RUNNING ROM CASES}

To run a case, the inputs are entered into a text file and the file is saved under the name "inputs.txt" in the installation directory of Tasmanian. Inputs are written in the following order, on one line separated by commas (Make sure there are no spaces before, after or in the middle of the string)

1. Room floor area in $\mathrm{m}^{2}$

2. Leak height in $m$

3. Door opening in $\mathrm{m}^{2}$

4. Ventilation flow rate in $\mathrm{cfm}$

5. Charge in $\mathrm{kg}$

6. Leak rate in $\mathrm{kg} / \mathrm{min}$

7. Molecular weight in $\mathrm{kg} / \mathrm{kmole}$

The "evaluateInterpolant.py" is then called from command window to run the ROM and write the outputs to a text file. An example is detailed below.

Example: run the ROM for the following inputs

\begin{tabular}{|l|l|}
\hline Room floor area, $\mathrm{m}^{2}$ & 20 \\
\hline Leak release height, $\mathrm{m}$ & 1.8 \\
\hline Door opening, $\mathrm{m}^{2}$ & 0.016 \\
\hline Ventilation flow rate, $\mathrm{cfm}$ & 200 \\
\hline Charge, $\mathrm{kg}$ & 3 \\
\hline Leak rate, $\mathrm{kg} / \mathrm{min}$ & 2.0 \\
\hline $\begin{array}{l}\text { Refrigerant molecular weight, } \\
\mathrm{kg} / \mathrm{kmol}\end{array}$ & 44 \\
\hline
\end{tabular}

1. First, create the input file

i. In the Tasmanian installation folder, create a new text file

ii. Enter the inputs in order

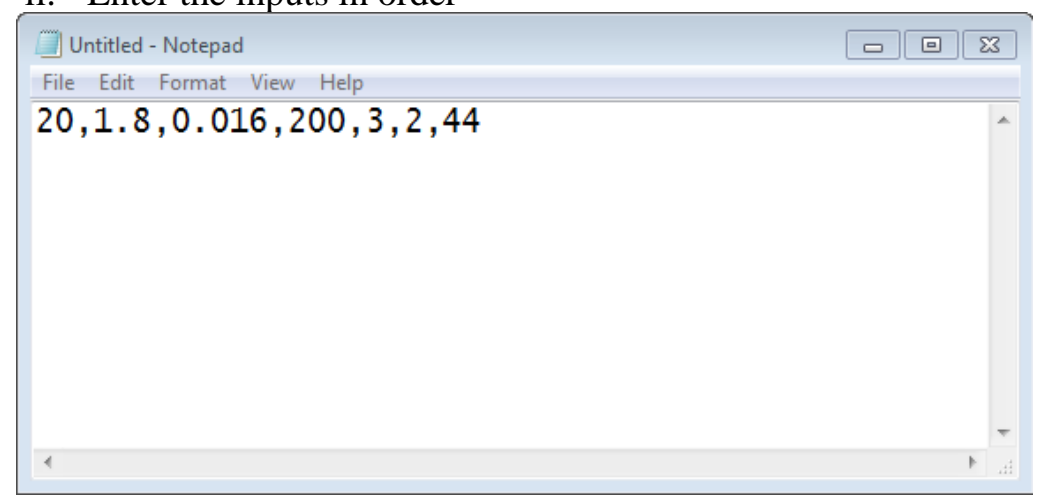

iii. Save the file with the name "inputs.txt"

2. Run the case

i. Open the command prompt (cmd.exe)

ii. Change directory to the installation folder of Tasmanian 


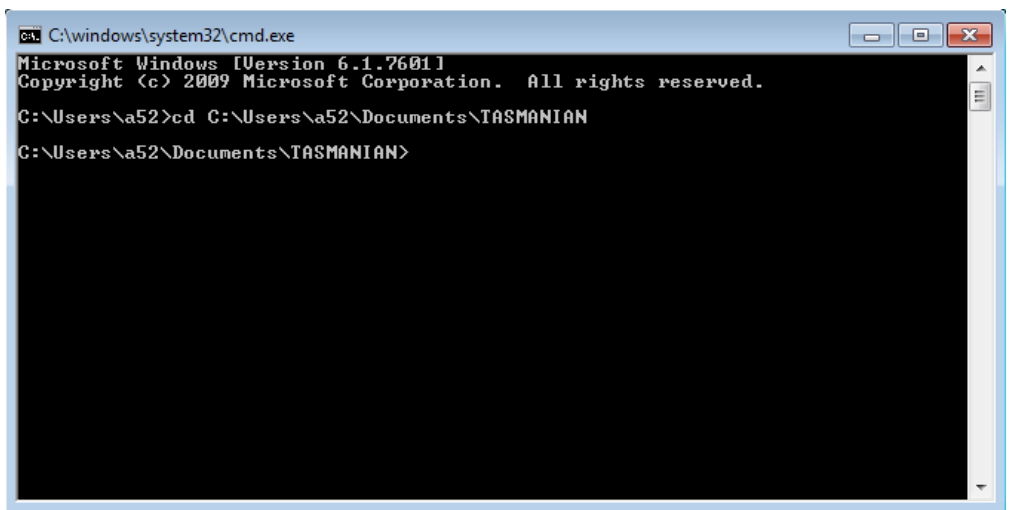

iii. Type the following command and hit enter: python evaluateInterpolant.py inputs.txt

iv. When the run is finished, the results will be displayed in the command prompt

v. The output is also written to "surrogate.txt" in the Tasmanian installation folder

3. Interpreting the output

i. The ROM outputs 396 values arranged as follows

1. The first value is the mean concentration across the full room and all times

2. The second value is the maximum concentration across the full room and all times

3. The next 10 values: Minimum concentration (\%) at $5,10,20,50,100,200,300,400,500$ and 600 seconds

4. The next 10 values: Mean concentration (\%) at $5,10,20,50,100,200,300,400,500$ and 600 seconds

5. The next 10 values: Maximum concentration (\%) at $5,10,20,50,100,200,300,400,500$ and 600 seconds

6. The next 364 values are grouped into 14 blocks. Each block contains the following outputs in order:

a. Mean flammable volume fraction (0-1)

b. Maximum flammable volume fraction (0-1)

c. Duration of flammable volume, seconds

d. Flammable volume fraction at 5 seconds

e. Flammable volume fraction at 10 seconds

f. Flammable volume fraction at 20 seconds

g. Flammable volume fraction at 50 seconds

h. Flammable volume fraction at 100 seconds

i. Flammable volume fraction at 200 seconds

j. Flammable volume fraction at 300 seconds

k. Flammable volume fraction at 400 seconds

1. Flammable volume fraction at 500 seconds

$\mathrm{m}$. Flammable volume fraction at 600 seconds

n. Mean accumulated fuel volume fraction (0-1)

o. Maximum accumulated fuel volume fraction (0-1)

p. Duration with some accumulated fuel volume, seconds

q. Accumulated fuel volume at 5 seconds

r. Accumulated fuel volume at 10 seconds

s. Accumulated fuel volume at 20 seconds

t. Accumulated fuel volume at 50 seconds 
u. Accumulated fuel volume at 100 seconds

v. Accumulated fuel volume at 200 seconds

w. Accumulated fuel volume at 300 seconds

$\mathrm{x}$. Accumulated fuel volume at 400 seconds

y. Accumulated fuel volume at 500 seconds

z. Accumulated fuel volume at 600 seconds

7. The blocks of data described in 6 are repeated 14 times for the following LFL and UFL in order

\begin{tabular}{|c|c|}
\hline $\begin{array}{c}\text { LFL } \\
(\% \mathbf{v} / \mathbf{v})\end{array}$ & $\begin{array}{c}\text { UFL } \\
(\boldsymbol{\%} \mathbf{v} / \mathbf{v})\end{array}$ \\
\hline 1.8 & 8.4 \\
\hline 1.9 & 8.5 \\
\hline 2.5 & 10.1 \\
\hline 2.7 & 36 \\
\hline 3 & 12.5 \\
\hline 3.3 & 26.2 \\
\hline 3.7 & 18 \\
\hline 3.8 & 15.4 \\
\hline 5 & 15 \\
\hline 6.2 & 12.3 \\
\hline 7.4 & 18.8 \\
\hline 8.1 & 17.4 \\
\hline 12 & 19 \\
\hline 13 & 33 \\
\hline
\end{tabular}

